\title{
Taxonomy and phylogeny of Phanerochaete sensu stricto (Polyporales, Basidiomycota) with emphasis on Chinese collections and descriptions of nine new species
}

\author{
Xu YL ${ }^{1}$, Cao $\mathrm{YF}^{1}$, Nakasone $\mathrm{KK}^{2}$, Chen $\mathrm{CC}^{3}$ and $\mathrm{He} \mathrm{SH}^{1^{*}}$ \\ ${ }^{1}$ School of Ecology and Nature Conservation, Beijing Forestry University, Beijing 100083, China \\ ${ }^{2}$ Center for Forest Mycology Research, Northern Research Station, U.S. Forest Service, Madison 53726, WI, U.S.A. \\ ${ }^{3}$ Department of Plant Pathology, National Chung Hsing University, Taichung 40227, Taiwan, China
}

Xu YL, Cao YF, Nakasone KK, Chen CC, He SH 2020 - Taxonomy and phylogeny of Phanerochaete sensu stricto with emphasis on Chinese collections and descriptions of nine new species. Mycosphere 11(1), 1527-1552, Doi 10.5943/mycosphere/11/1/12

\begin{abstract}
The taxonomy of Phanerochaete sensu stricto is studied herein by using both morphological and molecular methods. Phylogenetic analyses are based on a concatenated ITS1-5.8S-ITS2 and nrLSU sequence data of 50 taxa of Phanerochaete s.s. around the world. Among these are nine newly described and illustrated species $-P$. burdsallii, $P$. cinerea, $P$. hymenochaetoides, $P$. leptocystidiata, $P$. metuloidea, $P$. minor, $P$. sinensis, $P$. subrosea and $P$. yunnanensis. While $P$. burdsallii is from the U.S.A., the other new species were collected from China. In addition, nine species, $P$. bambucicola, $P$. citrinosanguinea, $P$. concrescens, $P$. cumulodentata, $P$. ericina, $P$. incarnata, $P$. livescens, $P$. magnoliae and $P$. taiwaniana are reported from mainland China for the first time. So far, 28 species of Phanerochaete s.s. from mainland China are confirmed by morphology and DNA sequence data. An identification key to all these species is presented. Phanerochaete fusca is determined to be a synonym of $P$. porostereoides.
\end{abstract}

Key words - corticioid fungi - Phanerochaetaceae - phlebioid fungi - white rot

\section{Introduction}

Basidiomycetous species are highly diverse and a number of new species have recently been published (Alvarado et al. 2018, Desjardin \& Perry 2018, Cui et al. 2019, Hapuarachchi et al. 2019). Many of these species have also been found to produce important secondary metabolites that have huge economic potential (Hapuarachchi et al. 2018a, b, Wu et al. 2019). Among those basidiomycetous species, the large corticioid genus Phanerochaete P. Karst. is widely distributed from boreal to tropical forests causing white rots on all kinds of wood and plays an important role in carbon cycling (Burdsall 1985). Morphologically, the genus is characterized by resupinate, membranaceous basidiomata with or without rhizomorphs, a monomitic hyphal system with primarily simple-septate generative hyphae, clavate basidia with four sterigmata, and smooth, thinwalled, inamyloid basidiospores (Eriksson et al. 1978, Burdsall 1985, Bernicchia \& Gorjón 2010). Recent molecular studies demonstrate that Phanerochaete sensu lato is polyphyletic and distributed across several lineages in the phlebioid clade of the Polyporales and also the Hymenochaetales (de Koker et al. 2003, Greslebin et al. 2004, Wu et al. 2010, Floudas \& Hibbett 2015, Miettinen et al. 2016, Justo et al. 2017, Chen et al. 2018). In several studies, Phanerochaete s.s. which includes the 
type, P. alnea (Fr.) P. Karst., formed a strongly supported clade in the Phanerochaetaceae (Floudas \& Hibbett 2015, Spirin et al. 2017). After the separation of several small genera based mainly on molecular evidence, the Phanerochaete s.s. lineage consists of about one third of the known species of Phanerochaete s.l. Recent phylogenetic studies on the other hand revealed morphologically cryptic taxa in Phanerochaete s.s. (e.g. Volobuev et al. 2015, Spirin et al. 2017, Phookamsak et al. 2019). The morphological diversity has been relooked into as well. For example, Phanerochaete krikophora nom. prov. has been observed to possess primarily clamped septa (Floudas \& Hibbett 2015) while P. inflata (B.S. Jia \& B.K. Cui) Miettinen possesses poroid hymenophore (Miettinen et al. 2016).

The diversity and taxonomy of Phanerochaete s.l. in China have been studied for the last 30 years (Wu 1990, 1995, 1998, 2000, 2004, 2007, Xiong \& Dai 2009, Wu et al. 2010, 2018a, b, Ghobad-Nejhad et al. 2015, Liu \& He 2016, Chen et al. 2018). Early studies focused on the flora of Taiwan Province and often based solely on morphology. About 170 specimens of Phanerochaete s.s. were collected by the corresponding author and colleagues during the last decade mostly from mainland China. In this paper, we present data of some of these specimens and contribute to the taxonomy of the Phlebioid clade (Justo et al. 2017) in China.

\section{Materials \& Methods}

\section{Morphological studies}

Voucher specimens are deposited at the herbaria of Beijing Forestry University, Beijing, China (BJFC), Centre for Forest Mycology Research, U.S. Forest Service, Madison, Wisconsin, U.S.A. (CFMR) and National Museum of Natural Science, Taichung, Taiwan, China (TNM). Freehand sections were made from dried basidiomata and mounted in $2 \%(\mathrm{w} / \mathrm{v})$ potassium hydroxide (KOH), 1\% (w/v) phloxine, Melzer's reagent (IKI) or cotton blue (CB). Microscopic examinations were carried out with a Nikon Eclipse 80i microscope (Nikon Corporation, Japan) at magnifications up to $1000 \times$. Drawings were made with the aid of a drawing tube. The following abbreviations are used: IKI- = neither amyloid nor dextrinoid, $\mathrm{CB}-=$ acyanophilous, $\mathrm{L}=$ mean spore length, $\mathrm{W}=$ mean spore width, $\mathrm{Q}=\mathrm{L} / \mathrm{W}$ ratio, $\mathrm{n}(\mathrm{a} / \mathrm{b})=$ number of spores $(\mathrm{a})$ measured from number of specimens (b). Color codes and names follow Kornerup \& Wanscher (1978).

\section{DNA extraction and sequencing}

A CTAB plant genomic DNA extraction Kit DN14 (Aidlab Biotechnologies Co., Ltd, Beijing, China) was used to extract total genomic DNA from dried specimens and perform the polymerase chain reaction (PCR), according to the manufacturer's instructions. The ITS1-5.8SITS2 region was amplified with the primer pair ITS5/ITS4 (White et al. 1990) by using the following procedure: initial denaturation at $95^{\circ} \mathrm{C}$ for $4 \mathrm{~min}$, followed by 34 cycles at $94^{\circ} \mathrm{C}$ for $40 \mathrm{~s}$, $58^{\circ} \mathrm{C}$ for $45 \mathrm{~s}$ and $72^{\circ} \mathrm{C}$ for $1 \mathrm{~min}$, and final extension at $72^{\circ} \mathrm{C}$ for $10 \mathrm{~min}$. The nrLSU D1-D2 $\begin{array}{llll}\text { region was amplified with the primer pair } & \text { LR0R/LR7 }\end{array}$ (http://www.biology.duke.edu/fungi/mycolab/primers.htm) by using the following procedure: initial denaturation at $94^{\circ} \mathrm{C}$ for $1 \mathrm{~min}$, followed by 34 cycles at $94^{\circ} \mathrm{C}$ for $30 \mathrm{~s}, 50^{\circ} \mathrm{C}$ for $1 \mathrm{~min}$ and $72^{\circ} \mathrm{C}$ for $1.5 \mathrm{~min}$, and final extension at $72^{\circ} \mathrm{C}$ for $10 \mathrm{~min}$. DNA sequencing was performed at Beijing Genomics Institute, and the sequences were deposited in GenBank (Table 1). BioEdit v.7.0.5.3 (Hall 1999) and Geneious v.11.1.15 (Kearse et al. 2012) were used for chromatogram check and contig assembly.

\section{Phylogenetic analyses}

The molecular phylogeny was inferred from a concatenated dataset of ITS1-5.8S-ITS2 and nrLSU sequences of 50 Phanerochaete s.s. taxa, which were confirmed to belong to Phanerochaete s.s. clade by previous studies and our pre-analyses. Phlebiopsis gigantea (Fr.) Jülich and Rhizochaete radicata (Henn.) Gresl., Nakasone \& Rajchenb. were selected as the outgroup (Floudas \& Hibbett 2015). The sequences of ITS and nrLSU were aligned separately using MAFFT 
v.7 (Katoh et al. 2017, http://mafft.cbrc.jp/alignment/server/) with the G-INS-i iterative refinement algorithm, and optimized manually in BioEdit v.7.0.5.3.. The separate alignments were concatenated using Mesquite v.3.5.1 (Maddison \& Maddison 2018). The combined alignments were deposited in TreeBase (http://treebase.org/treebase-web/home.html, submission ID: 26185).

Maximum parsimony (MP), Maximum likelihood (ML) analyses and Bayesian inference (BI) were carried out by using PAUP* v.4.0b10 (Swofford 2002), RAxML v.8.2.10 (Stamatakis 2014) and MrBayes 3.2.6 (Ronquist et al. 2012) respectively. In MP analysis, trees were generated using 100 replicates of random stepwise addition of sequence and tree-bisection reconnection (TBR) branch-swapping algorithm with all characters given equal weight. Branch supports for all parsimony analyses were estimated by performing 1000 bootstrap replicates with a heuristic search of 10 random-addition replicates for each bootstrap replicate. In ML analysis, statistical support values were obtained using rapid bootstrapping with 1000 replicates, with default settings used for other parameters. For BI, the best-fit substitution model was estimated with jModeltest v.2.17 (Darriba et al. 2012). Four Markov chains were run for 2,700,000 generations until the split deviation frequency value was lower than 0.01 . Trees were sampled every 100th generation. The first quarter of the trees, which represented the burn-in phase of the analyses, were discarded and the remaining trees were used to calculate posterior probabilities (BPP) in the majority rule consensus tree.

Table 1 Species and sequences used in the phylogenetic analyses. New species are in bold with type specimens mark with *.

\begin{tabular}{|c|c|c|c|c|c|}
\hline Taxa & Voucher & Locality & ITS & nLSU & Literature \\
\hline Phanerochaete albida & He 4554 & China & MT235655 & MT248133 & This study \\
\hline P. alnea & OM 8110 & Finland & KP135171 & - & $\begin{array}{l}\text { Floudas \& } \\
\text { Hibbett } 2015\end{array}$ \\
\hline P. alnea & KHL 12054 & Norway & EU118653 & EU118653 & Larsson 2007 \\
\hline P. alnea subsp. lubrica & Spirin 8229 & U.S.A. & KU893876 & - & Spirin et al. 2017 \\
\hline P. argillacea & Wu 9712-18 & China & - & GQ470656 & Wu et al. 2010 \\
\hline P. arizonica & RLG-10248-Sp & U.S.A. & KP135170 & KP135239 & $\begin{array}{l}\text { Floudas \& } \\
\text { Hibbett } 2015\end{array}$ \\
\hline P. australis & Не 6013 & China & MT235656 & MT248136 & This study \\
\hline P. australis & HHB-7105-Sp & U.S.A. & KP135081 & KP135240 & $\begin{array}{l}\text { Floudas \& } \\
\text { Hibbett } 2015\end{array}$ \\
\hline P. australosanguinea & 20098 Tell & Chile & - & MH233928 & $\begin{array}{l}\text { Phookamsak et } \\
\text { al. } 2019\end{array}$ \\
\hline P. australosanguinea & 20102 Tell & Chile & - & MH233929 & $\begin{array}{l}\text { Phookamsak et } \\
\text { al. } 2019\end{array}$ \\
\hline P. bambucicola & He 3606 & China & MT235657 & MT248137 & This study \\
\hline P. bambucicola & Wu 0707-2 & China & MF399404 & MF399395 & Wu et al. 2018b \\
\hline P. brunnea & Не 4192 & China & MT235658 & MT248138 & This study \\
\hline P. brunnea & Нe 1873 & China & KX212220 & KX212224 & Liu \& He 2016 \\
\hline P. burdsallii & He $2066^{*}$ & U.S.A. & MT235690 & MT248177 & This study \\
\hline P. burdsallii & CFMR: RF9JR & U.S.A. & KU668973 & - & - \\
\hline P. burdsallii & FP-101018-sp & U.S.A. & AY219348 & - & $\begin{array}{l}\text { de Koker et al. } \\
2003\end{array}$ \\
\hline P. burtii & HHB-4618-Sp & U.S.A. & KP135117 & KP135241 & $\begin{array}{l}\text { Floudas \& } \\
\text { Hibbett } 2015\end{array}$ \\
\hline P. canobrunnea & He 5726 & Sri Lanka & MT235659 & MT248139 & This study \\
\hline P. canobrunnea & CHWC 1506-66 & China & LC412095 & LC412104 & Wu et al. 2018a \\
\hline P. canolutea & Wu 9211-105 & China & - & GQ470641 & Wu et al. 2010 \\
\hline P. carnosa & He 5172 & China & MT235660 & MT248140 & This study \\
\hline P. carnosa & HHB-9195 & U.S.A. & KP135129 & KP135242 & $\begin{array}{l}\text { Floudas \& } \\
\text { Hibbett } 2015\end{array}$ \\
\hline P. chrysosporium & He 5778 & Sri Lanka & MT235661 & MT248141 & This study \\
\hline
\end{tabular}


Table 1 Continued.

\begin{tabular}{|c|c|c|c|c|c|}
\hline Taxa & Voucher & Locality & ITS & nLSU & Literature \\
\hline P. chrysosporium & HHB-6251-Sp & U.S.A. & KP135094 & KP135246 & $\begin{array}{l}\text { Floudas \& } \\
\text { Hibbett } 2015\end{array}$ \\
\hline P. cinerea & Не $5998^{*}$ & China & - & MT248171 & This study \\
\hline P. cinerea & Не 6003 & China & - & MT248172 & This study \\
\hline P. citrinosanguinea & Не 4298 & China & MT235691 & MT248178 & This study \\
\hline P. citrinosanguinea & FP-105385-Sp & U.S.A. & KP135100 & KP135234 & $\begin{array}{l}\text { Floudas \& } \\
\text { Hibbett } 2015\end{array}$ \\
\hline P. concrescens & Не 4657 & China & MT235662 & MT248142 & This study \\
\hline P. concrescens & Spirin 7322 & Russia & KP994380 & KP994382 & $\begin{array}{l}\text { Volobuev et al. } \\
2015\end{array}$ \\
\hline P. cumulodentata & Не 2995 & China & MT235664 & MT248144 & This study \\
\hline P. cumulodentata & LE 298935 & Russia & КР994359 & КР994386 & $\begin{array}{l}\text { Volobuev et al. } \\
2015\end{array}$ \\
\hline P. cystidiata & Не 4224 & China & MT235665 & MT248145 & This study \\
\hline P. cystidiata & Wu 1708-326 & China & LC412097 & LC412100 & Wu et al. 2018a \\
\hline P. deflectens & FCUG 2777 & Turkey & - & GQ470644 & Wu et al. 2010 \\
\hline P. ericina & He 4285 & China & МТ235666 & МТ248146 & This study \\
\hline P. ericina & HHB-2288 & U.S.A. & KP135167 & KP135247 & $\begin{array}{l}\text { Floudas \& } \\
\text { Hibbett } 2015\end{array}$ \\
\hline P. fusca & Wu 1409-163 & China & LC412099 & LC412106 & Wu et al. 2018a \\
\hline P. hymenochaetoides & He $5988^{*}$ & China & - & MT248173 & This study \\
\hline P. incarnata & He 20120728-1 & China & МТ235669 & МT248149 & This study \\
\hline P. incarnata & WEI 16-075 & China & MF399406 & MF399397 & Wu et al. 2018b \\
\hline P. inflata & Dai 10376 & China & JX623929 & JX644062 & Jia et al. 2014 \\
\hline$P$. inflata & Cui 7712 & China & JX623930 & JX644063 & Jia et al. 2014 \\
\hline $\begin{array}{l}\text { P. krikophora nom. } \\
\text { prov. }\end{array}$ & HHB-5796 & U.S.A. & KP135164 & KP135268 & $\begin{array}{l}\text { Floudas \& } \\
\text { Hibbett } 2015\end{array}$ \\
\hline P. laevis & He 20120917-8 & China & MT235670 & MT248150 & This study \\
\hline P. laevis & HHB-15519 & U.S.A. & KP135149 & KP135249 & $\begin{array}{l}\text { Floudas \& } \\
\text { Hibbett } 2015\end{array}$ \\
\hline P. leptocystidiata & He $5853^{*}$ & China & MT235685 & MT248168 & This study \\
\hline P. leptocystidiata & Dai 10468 & China & MT235684 & MT248167 & This study \\
\hline$P$. livescens & He 5010 & China & MT235671 & MT248151 & This study \\
\hline$P$. livescens & FD-106 & U.S.A. & KP135070 & KP135253 & $\begin{array}{l}\text { Floudas \& } \\
\text { Hibbett } 2015\end{array}$ \\
\hline P. magnoliae & Не 3321 & China & MT235672 & MT248152 & This study \\
\hline P. magnoliae & HHB-9829-Sp & U.S.A. & KP135089 & KP135237 & $\begin{array}{l}\text { Floudas \& } \\
\text { Hibbett } 2015\end{array}$ \\
\hline P. metuloidea & He $2565^{*}$ & China & - & MT248163 & This study \\
\hline P. metuloidea & Не 2766 & China & MT235682 & MT248164 & This study \\
\hline P. minor & He $3988^{*}$ & China & MT235686 & MT248170 & This study \\
\hline P. minor & Не 3977 & China & - & MT248169 & This study \\
\hline P. parmastoi & He 4570 & China & MT235673 & MT248153 & This study \\
\hline P. parmastoi & Wu 880313-6 & China & - & GQ470654 & Wu et al. 2010 \\
\hline P. porostereoides & He 1902 & China & KX212217 & KX212221 & Liu \& He 2016 \\
\hline P. porostereoides & He 5365 & China & - & MT248154 & This study \\
\hline P. pseudomagnoliae & PP-25 & South Africa & KP135091 & KP135250 & $\begin{array}{l}\text { Floudas \& } \\
\text { Hibbett } 2015\end{array}$ \\
\hline P. pseudosanguinea & FD-244 & U.S.A. & KP135098 & KP135251 & $\begin{array}{l}\text { Floudas \& } \\
\text { Hibbett } 2015\end{array}$ \\
\hline P. rhodella & FD-18 & U.S.A. & KP135187 & KP135258 & $\begin{array}{l}\text { Floudas \& } \\
\text { Hibbett } 2015\end{array}$ \\
\hline P. robusta & Wu 1109-69 & China & MF399409 & MF399400 & Wu et al. $2018 \mathrm{~b}$ \\
\hline
\end{tabular}


Table 1 Continued.

\begin{tabular}{|c|c|c|c|c|c|}
\hline Taxa & Voucher & Locality & ITS & nLSU & Literature \\
\hline $\begin{array}{l}\text { P. robusta } \\
\text { (aurantiobadia) }\end{array}$ & $\begin{array}{l}\text { Ghobad-Nejhad } \\
2288\end{array}$ & China & KP127068 & KP127069 & $\begin{array}{l}\text { Ghobad-Nejhad } \\
\text { et al. } 2015\end{array}$ \\
\hline P. sanguinea & HHB-7524 & U.S.A. & KP135101 & KP135244 & $\begin{array}{l}\text { Floudas \& } \\
\text { Hibbett } 2015\end{array}$ \\
\hline P. sanguineocarnosa & FD-359 & U.S.A. & KP135122 & KP135245 & $\begin{array}{l}\text { Floudas \& } \\
\text { Hibbett } 2015\end{array}$ \\
\hline P. sinensis & He 4660* & China & MT235688 & MT248175 & This study \\
\hline P. sinensis & GC 1809-56 & China & MT235689 & МT248176 & This study \\
\hline P. sordida & He 5400 & China & MT235676 & MT248157 & This study \\
\hline P. sordida & FD-241 & U.S.A. & KP135136 & KP135252 & $\begin{array}{l}\text { Floudas \& } \\
\text { Hibbett } 2015\end{array}$ \\
\hline P. stereoides & He 5824 & Sri Lanka & MT235677 & MT248158 & This study \\
\hline P. stereoides & He 2309 & China & KX212219 & KX212223 & Liu \& He 2016 \\
\hline P. subceracea & FP-105974-R & U.S.A. & KP135162 & KP135255 & $\begin{array}{l}\text { Floudas \& } \\
\text { Hibbett } 2015\end{array}$ \\
\hline P. subrosea & He $2421^{*}$ & China & MT235687 & МT248174 & This study \\
\hline P. taiwaniana & He 5269 & Vietnam & MT235680 & MT248161 & This study \\
\hline P. taiwaniana & Wu 0112-13 & China & MF399412 & MF399403 & Wu et al. $2018 b$ \\
\hline P. thailandica & 2015_07 & Thailand & MF467737 & - & $\begin{array}{l}\text { Sádlíková \& } \\
\text { Kout } 2017\end{array}$ \\
\hline P. velutina & Не 3079 & China & MT235681 & МT248162 & This study \\
\hline P. velutina & Kotiranta 25567 & Russia & КР994354 & КР994387 & $\begin{array}{l}\text { Volobuev et al. } \\
2015\end{array}$ \\
\hline P. yunnanensis & Не $2719 *$ & China & МT235683 & MT248166 & This study \\
\hline P. yunnanensis & Не 2697 & China & - & MT248165 & This study \\
\hline Phlebiopsis gigantea & FP-70857-Sp & U.S.A. & KР135390 & KP135272 & $\begin{array}{l}\text { Floudas \& } \\
\text { Hibbett } 2015\end{array}$ \\
\hline Rhizochaete radicata & FD-123 & U.S.A. & KP135407 & KP135279 & $\begin{array}{l}\text { Floudas \& } \\
\text { Hibbett } 2015\end{array}$ \\
\hline
\end{tabular}

\section{Results}

\section{Phylogenetic analyses}

The concatenated dataset contained 72 ITS and 80 nrLSU sequences from 85 samples representing 50 Phanerochaete s.s. taxa and the outgroup (Table 1). Thirty ITS and 37 nrLSU sequences were generated for this study. The dataset had an aligned length of 2119 characters, of which 379 are parsimony-informative. MP analysis yielded two equally parsimonious trees (TL = $1568, \mathrm{CI}=0.467, \mathrm{RI}=0.716, \mathrm{RC}=0.335, \mathrm{HI}=0.533)$. jModelTest suggested $\mathrm{GTR}+\mathrm{I}+\mathrm{G}$ to be the best-fit models of nucleotide evolution for BI. The average standard deviation of split frequencies of BI was 0.009147 at the end of the run. ML and BI analyses resulted in almost identical tree topologies compared to the MP analysis. Only the MP tree is provided in Fig. 1 with the parsimony bootstrap values ( $\geq 50 \%$, front), likelihood bootstrap values $(\geq 50 \%$, middle) and Bayesian posterior probabilities $(\geq 0.95$, back) labelled along the branches.

In the tree, the nine new species, $P$. burdsallii, $P$. cinerea, $P$. hymenochaetoides, $P$. leptocystidiata, P. metuloidea, P. minor, P. sinensis, $P$. subrosea and $P$. yunnanensis formed distinct lineages respectively. For some species, the sequences generated in this study formed strongly supported lineages with published GenBank sequences.

Phanerochaete burdsallii Y.L. Xu, Nakasone \& S.H. He, sp. nov.

Fig. 2

MycoBank: MB 835445; Facesoffungi number: FoF 08031

Type - U.S.A., Wisconsin State, Dane County, Madison city, Hoyt park, on fallen angiosperm trunk, 3 September 2014, He 2066 (BJFC 018724, holotype, isotype in CFMR). 
Etymology - To honor Harold Hugh Burdsall, Jr. (CFMR, U.S.A.) for his contributions to the taxonomy of Phanerochaete.

Fruiting body - Basidiomata annual resupinate, effused, loosely adnate, easily detached from substrate, membranaceous, fragile when dry, first as small patches, later confluent up to $10 \mu \mathrm{m}$ long, $3 \mathrm{~cm}$ wide. Hymenophore smooth, light orange [6A(4-5)], greyish orange [6B(4-6)] to brownish orange [6C(5-8)], turning reddish brown in $\mathrm{KOH}$, uncracked; margin thinning out, fibrillose, with hyphal cords, lighter than hymenophore surface, white (6A1) to light orange [6A(4-5)].

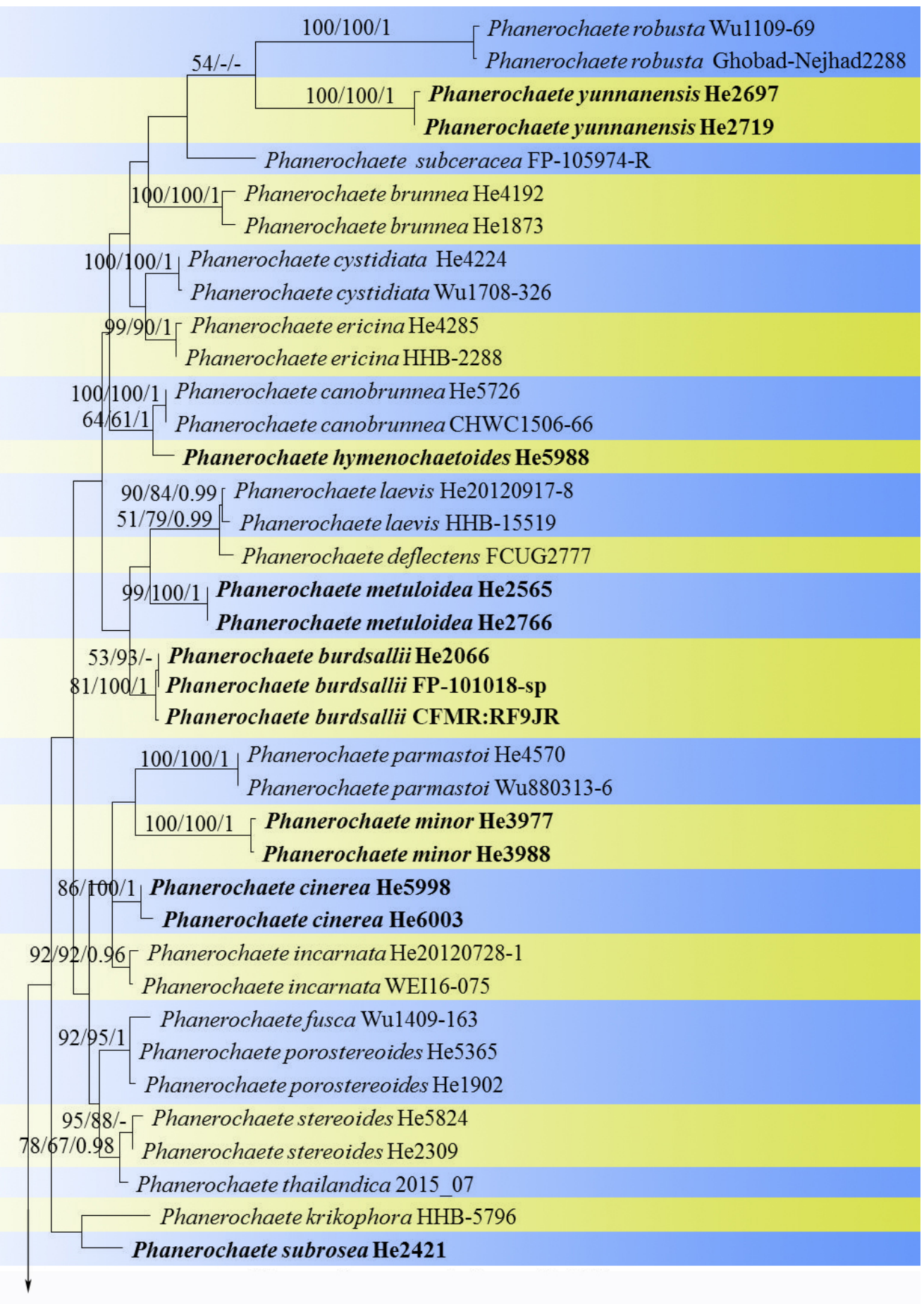

Figure 1 - Phylogenetic tree obtained from maximum parsimony analysis of a concatenated ITS and nrLSU sequence data of Phanerochaete s.s. Branches are labelled with parsimony bootstrap values ( $\geq 50 \%$, front), likelihood bootstrap values $(\geq 50 \%$, middle) and Bayesian posterior probabilities ( $\geq 0.95$, back). New species are shown in bold. 


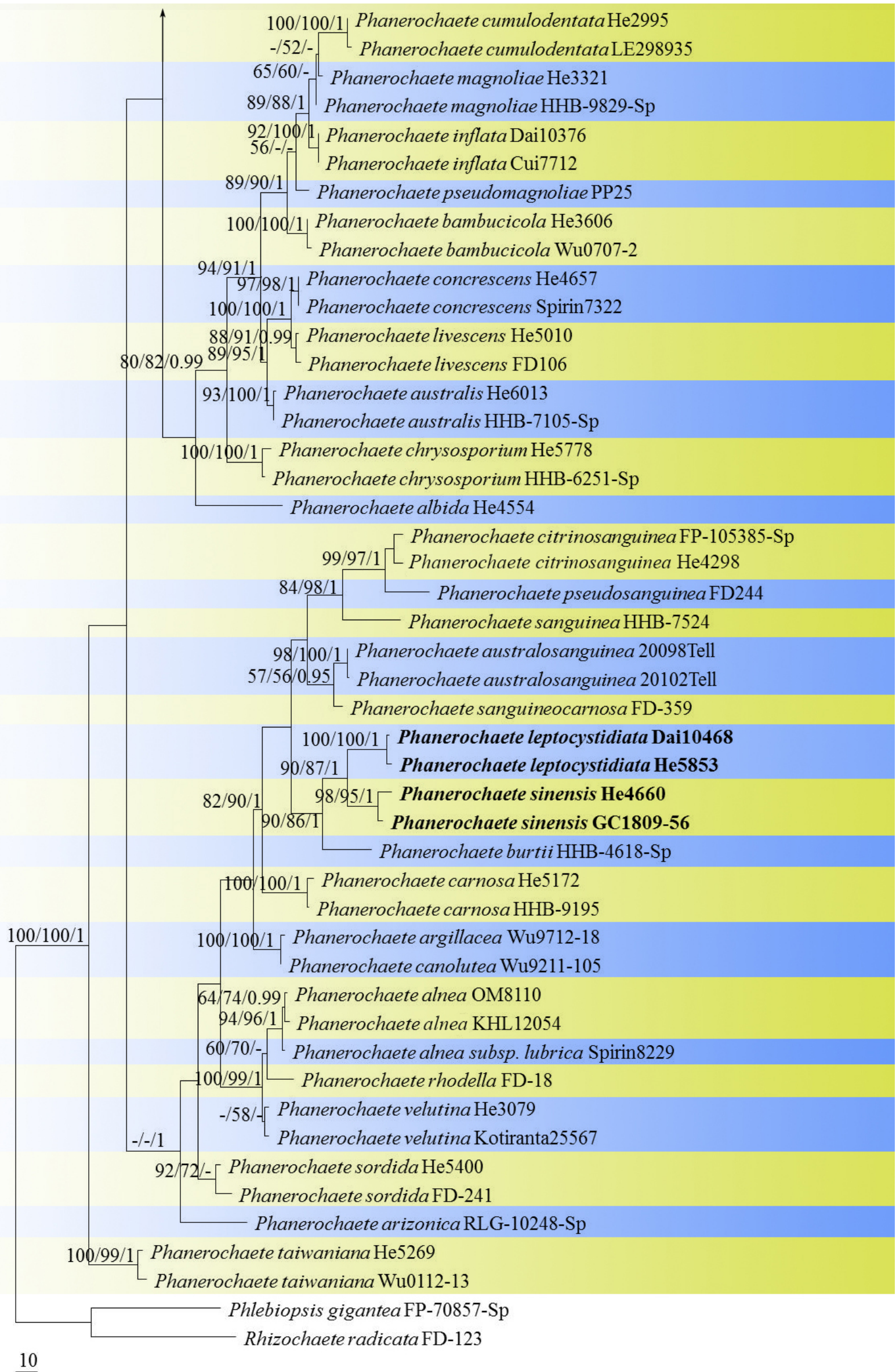

Figure 1 - Continued. 

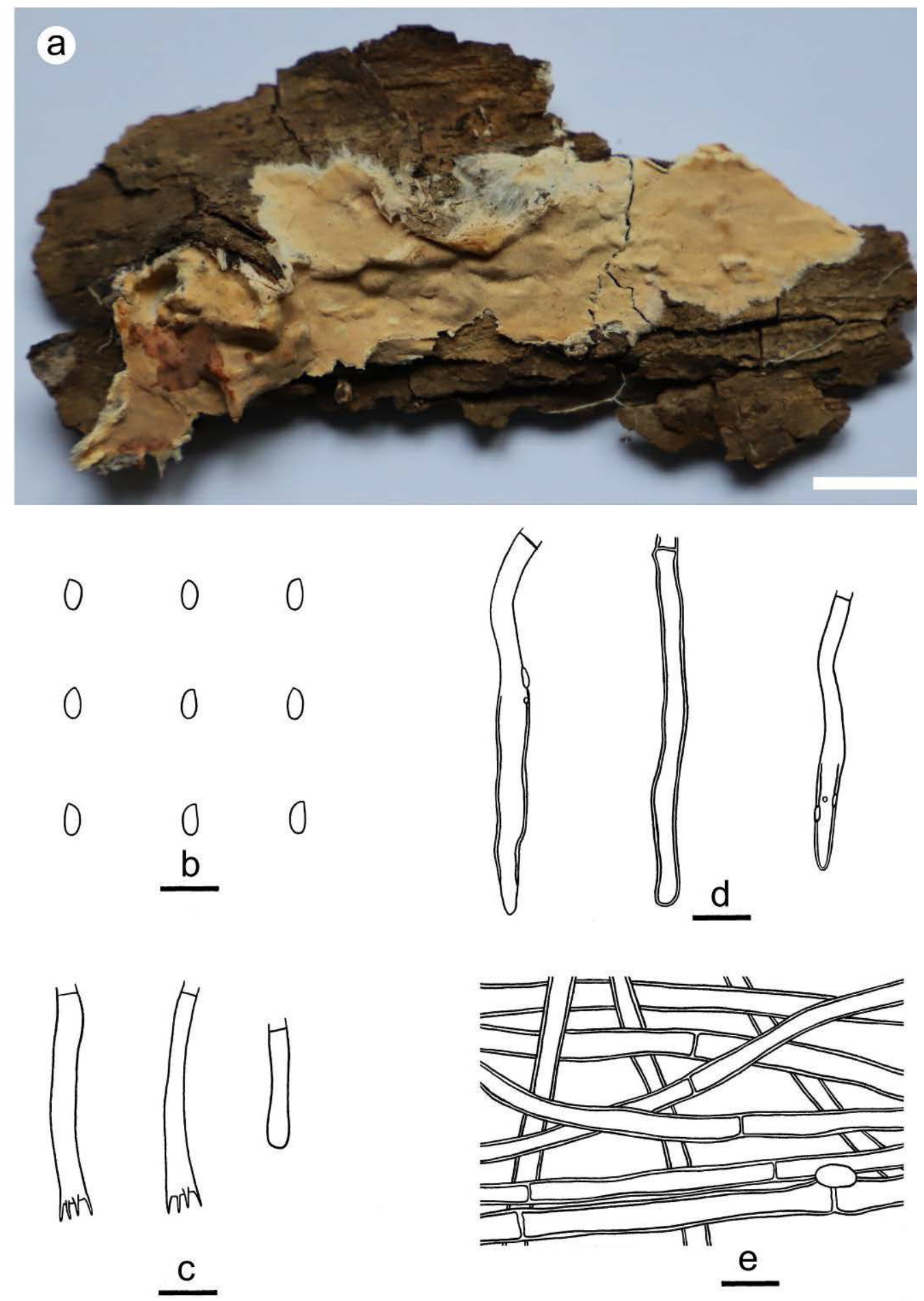

Figure 2 - Phanerochaete burdsallii (From the holotype He 2066). a basidiomata. b basidiospores. c basidia and a basidiole. d cystidia. e hyphae from subiculum. Scale bars: a $=1 \mathrm{~cm}, \mathrm{~b}-\mathrm{e}=10 \mu \mathrm{m}$.

Microscopic structures - Hyphal system monomitic; generative hyphae mostly simpleseptate, occasionally with single or double clamp connections. Subicular hyphae colorless, thickwalled, sparsely encrusted with fine crystals, moderately branched and septate, loosely interwoven, more or less parallel to substrate, 4-7 $\mu \mathrm{m}$ in diam. Cystidia subulate to subcylindrical with tapered or obtuse apex, colorless, thin- to slightly thick-walled, sparsely encrusted with small crystals in the upper part, projecting above the hymenium, with a basal simple septum, 50-90 × 3.5-6 $\mu \mathrm{m}$. Basidia clavate to cylindrical, colorless, thin-walled, with a basal simple septum and four sterigmata, 22-38 
$\times$ 4.5-6 $\mu \mathrm{m}$; basidioles numerous, similar to basidia but smaller. Basidiospores ellipsoid, colorless, thin-walled, smooth, IKI-, CB-, (5-) 5.3-6 (-6.5) $\times 2.5-3(-3.2) \mu \mathrm{m}, \mathrm{L}=5.7 \mu \mathrm{m}, \mathrm{W}=2.8 \mu \mathrm{m}, \mathrm{Q}$ $=2(\mathrm{n}=30 / 1)$.

Additional specimens examined - U.S.A., Wisconsin State, on rotten Populus trunk, 2013, D. Richter (CFMR: RF9JR); Minnesota State, Cloquet, on fallen angiosperm trunk, 26 August 1972, FP-101018-sp (CFMR).

Distribution - Wisconsin and Minnesota States, north central U.S.A.

Notes - Phanerochaete burdsallii is characterized by its rhizomorphic basidiomata that turns reddish brown in $\mathrm{KOH}$ and presence of encrusted cystidia. Phanerochaete burdsallii is similar to $P$. laevis (Fr.) J. Erikss. \& Ryvarden by sharing encrusted cystidia and same-sized basidiospores, but the latter species differs in having lighter basidiomata and thin-walled subicular hyphae (Burdsall 1985, Bernicchia \& Gorjón 2010). In addition, P. laevis is widely distributed in Europe and North America, while $P$. burdsallii is known to date only in Wisconsin and Minnesota. Phanerochaete sordida (P. Karst.) J. Erikss. \& Ryvarden is also similar to P. burdsallii, but differs in having thicker basidiomata and more loosely interwoven subicular hyphae that are rigid with thickened walls (Bernicchia \& Gorjón 2010). In the phylogenetic tree, three samples of $P$. burdsallii formed a distinct lineage sister to P. laevis and P. metuloidea (Fig. 1). Phanerochaete metuloidea described as new species below resembles $P$. burdsallii, but differs in having softer basidiomata with more heavily encrusted cystidia and larger basidia $(40-70 \times 5-8.5 \mu \mathrm{m})$.

Phanerochaete cinerea Y.L. Xu \& S.H. He, sp. nov.

Fig. 3

MycoBank: MB 835446; Facesoffungi number: FoF 08032

Type - China, Hainan Province, Changjiang County, Bawangling Nature Reserve, on small diameter bamboo, 4 July 2019, He 5998 (BJFC 030874, holotype).

Etymology - Refers to the grey hymenophore surface.

Fruiting body - Basidiomata annual, resupinate, effused, adnate, detachable from substrate, membranaceous to coriaceous, first as many small patches, later confluent up to $15 \mu \mathrm{m}$ long, $3 \mathrm{~cm}$ wide. Hymenophore smooth, grey (6C1-6D1), brownish grey (6C2-6D2) to greyish brown (6D3), slightly darkening in $\mathrm{KOH}$, uncracked; margin thinning out, velvety, distinct, white (6A1), usually with a dark line near hymenophore when juvenile, becoming indistinct, concolorous or darker with hymenophore surface with age.

Microscopic structures - Hyphal system monomitic; generative hyphae simple-septate. Subicular hyphae yellowish brown, thick-walled to distinctly thick-walled, smooth, moderately branched and septate, tightly interwoven, more or less parallel to substrate, $3-5 \mu \mathrm{m}$ in diam. Cystidia absent. Hyphida present, yellowish brown, thick-walled, branched. Basidia clavate, colorless, thin-walled, with a basal simple septum and four sterigmata, 20-30 $\times 4-5 \mu \mathrm{m}$; basidioles numerous, similar to basidia but smaller. Basidiospores subcylindrical, colorless, thin-walled, smooth, IKI-, CB-, 4.8-5.6 (-6) × 2-2.5 (-2.8) $\mu \mathrm{m}, \mathrm{L}=5.2 \mu \mathrm{m}, \mathrm{W}=2.2 \mu \mathrm{m}, \mathrm{Q}=2.4(\mathrm{n}=30 / 1)$.

Additional specimen examined - China, Hainan Province, Changjiang County, Bawangling Nature Reserve, on small dead bamboo, 4 July 2019, He 6003 (BJFC 030879).

Distribution - Hainan Province, southern tropical China.

Notes - Phanerochaete cinerea is characterized by grey basidiomata on small diameter bamboo, absence of cystidia, brown subicular hyphae, and subcylindrical basidiospores. Phanerochaete stereoides Sheng $\mathrm{H}$. Wu is similar to $P$. cinerea by sharing grey hymenophore and brown subicular hyphae, but differs in having effuse-reflexed and tough basidiomata and leptocystidia (Wu 1995). Phanerochaete brunnea Sheng $\mathrm{H}$. Wu also has brown subicular hyphae and lacks cystidia, but differs from $P$. cinerea in having soft basidiomata and loosely interwoven subicular hyphae and lacking hyphidia (Wu 1990). Phanerochaete porostereoides S.L. Liu \& S.H. He differs from $P$. cinerea in having brown, tough, coriaceous basidiomata, slightly wider basidiospores (4.7-5.3 × 2.5-3.1 $\mu \mathrm{m})$ and a distribution in temperate regions (Liu \& He 2016). Phanerochaete thailandica Kout \& Sádlíková differs from $P$. cinerea in having leptocystidia and 
larger basidiospores (7-8 × 4-4.5 $\mu$, Sádlíková \& Kout 2017). In the phylogenetic tree, two samples of $P$. cinerea formed a distinct lineage from morphologically similar species (Fig. 1).
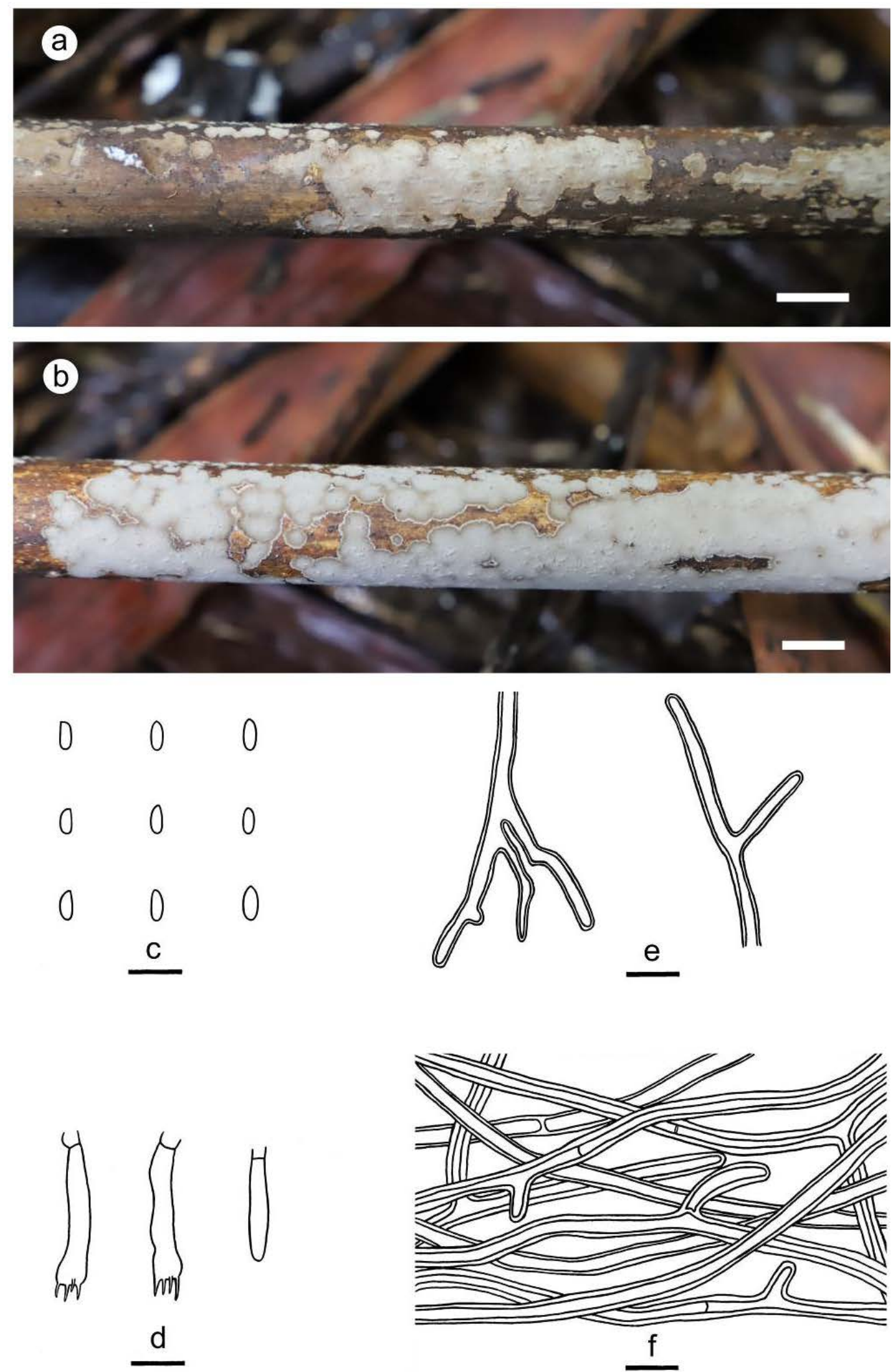

Figure 3 - Phanerochaete cinerea (a, c-f: from the holotype He 5998, b: from He 6003). a-b basidiomata. c basidiospores. $\mathrm{d}$ basidia and a basidiole. e hyphidia. $\mathrm{f}$ hyphae from subiculum. Scale bars: $\mathrm{a}-\mathrm{b}=1 \mathrm{~cm}, \mathrm{c}-\mathrm{f}=10 \mu \mathrm{m}$ 
Phanerochaete hymenochaetoides Y.L. Xu \& S.H. He, sp. nov.

Fig. 4 MycoBank: MB 835447; Facesoffungi number: FoF 08033

Type - China, Hainan Province, Lingshui County, Diaoluoshan Nature Reserve, on fallen angiosperm branch, 2 July 2019, He 5988 (BJFC 030864, holotype).

Etymology - Refers to the Hymenochaete-like basidiomata.
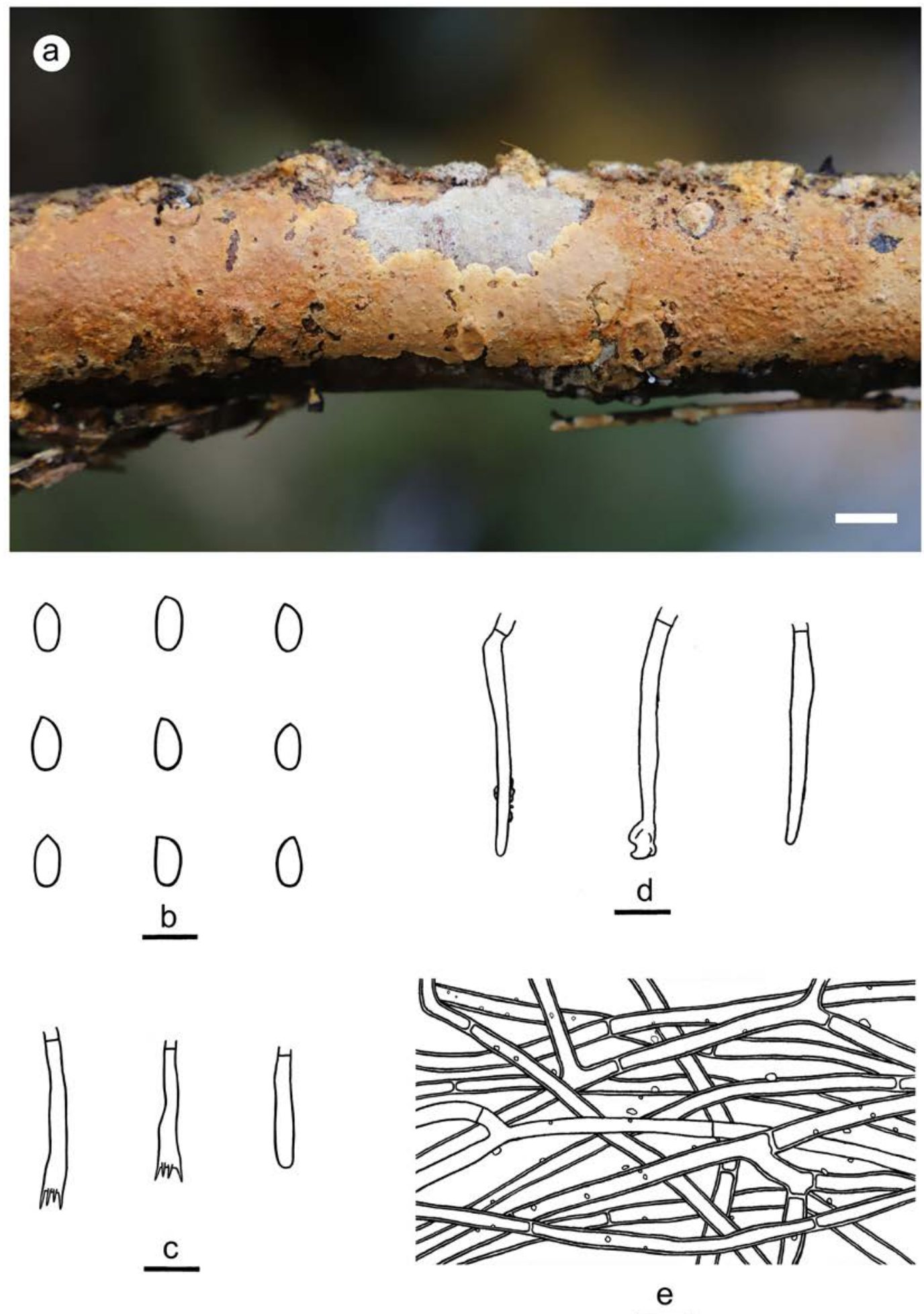

Figure 4 - Phanerochaete hymenochaetoides (from the holotype He5988). a basidiomata. b basidiospores. c basidia and a basidiole. d cystidia. e hyphae from subiculum. Scale bars: $\mathrm{a}=1 \mathrm{~cm}$, $\mathrm{b}=5 \mu \mathrm{m}, \mathrm{c}-\mathrm{e}=10 \mu \mathrm{m}$. 
Fruiting body - Basidiomata annual, resupinate, effused, closely adnate, undetachable from substrate, membranaceous to coriaceous, up to $20 \mu \mathrm{m}$ long, $3.5 \mathrm{~cm}$ wide. Hymenophore smooth, greyish orange [6B(4-6)], brownish orange [6C(4-6)] to light brown [6D(4-6)], turning reddish brown in $\mathrm{KOH}$, uncracked; margin thinning out, lighter or concolorous with hymenophore surface.

Microscopic structures - Hyphal system monomitic; generative hyphae mostly simple-septate, occasionally with clamp connections. Subicular hyphae colorless to light yellow, thin- to thickwalled, encrusted with yellow resinous granules, frequently branched and septate, interwoven, more or less parallel to substrate, $2-5 \mu \mathrm{m}$ in diam. Cystidia subulate, tapered toward apex, colorless, thinwalled, encrusted with crystals at apex, projecting above the hymenium, with a basal simple septum, 30-45 × 3-4 $\mu \mathrm{m}$. Basidia clavate, colorless, thin-walled, with a basal simple septum and four sterigmata, $15-45 \times 3.5-5 \mu \mathrm{m}$; basidioles numerous, similar to basidia but smaller. Basidiospores ellipsoid, colorless, thin-walled, smooth, IKI-, CB-, 4-5 (-5.2) $\times 2-2.8 \mu \mathrm{m}, \mathrm{L}=4.3 \mu \mathrm{m}, \mathrm{W}=2.3$ $\mu \mathrm{m}, \mathrm{Q}=1.9(\mathrm{n}=30 / 1)$.

Distribution - Hainan Province, southern tropical China.

Notes - Phanerochaete hymenochaetoides is characterized by the yellow to yellowish brown basidiomata, narrow encrusted subicular hyphae and presence of encrusted cystidia. In the phylogenetic tree, $P$. hymenochaetoides is closely related to $P$. canobrunnea Sheng H. Wu, C.C. Chen \& C.L. Wei, but differs in having greyish brown basidiomata, a dimitic hyphal system with brown subicular hyphae, wider generative hyphae (4-9 $\mu \mathrm{m}$ in diam.) and lacking cystidia (Fig. 1, Wu et al. 2018a). Phanerochaete cystidiata Sheng H. Wu, C.C. Chen \& C.L. Wei is similar to P. hymenochaetoides by sharing encrusted cystidia, but differs in having cream to yellow basidiomata with fibrillose margin and slightly larger cystidia $(40-60 \times 4-5.5 \mu \mathrm{m}$; Wu et al. 2018a). Phanerochaete robusta Parmasto is similar to $P$. hymenochaetoides by sharing the yellow basidiomata, but differs in having two kinds of cystidia without encrustation, larger basidiospores (5.5-7 × 2.4-2.9 $\mu \mathrm{m})$ and a boreal distribution (Wu et al. 2018b).

Phanerochaete leptocystidiata Y.L. Xu \& S.H. He, sp. nov.

Fig. 5

MycoBank: MB 835448; Facesoffungi number: FoF 08034

Type - China, Guangdong Province, Renhua County, Danxiashan Nature Reserve, on fallen angiosperm trunk, 4 June 2019, He 5853 (BJFC 030728, holotype).

Etymology - Refers to the presence of typical leptocystidia.

Fruiting body - Basidiomata annual, resupinate, effused, loosely adnate, easily detached from substrate, pellicular to membranaceous, up to $10 \mu \mathrm{m}$ long, $8 \mathrm{~cm}$ wide. Hymenophore smooth to tuberculate, white (6A1) when fresh, becoming smooth, pale orange (6A3), orange grey (6B2) to greyish orange [6B(3-5)] when dry, slightly darkening in $\mathrm{KOH}$, sparsely cracked with age; margin thinning out, fibrillose, concolorous with hymenophore surface; hyphal cords greyish orange [6B(4-5)] to orange [6B(7-8)], turning reddish brown in $\mathrm{KOH}$.

Microscopic structures - Hyphal system monomitic; generative hyphae mostly simple-septate, occasionally with single or double clamp connections. Subicular hyphae colorless, slightly thickwalled, encrusted with crystals, rarely branched and septate, loosely interwoven, more or less parallel to substrate, 3-7 $\mu \mathrm{m}$ in diam. Cystidia subulate, tapered toward apex, colorless, thin-walled, smooth or rarely encrusted at apex, projecting above the hymenium, with a basal simple septum, 30-70 × 4-6 $\mu \mathrm{m}$. Basidia clavate, colorless, thin-walled, with a basal simple septum and four sterigmata, 24-30 × 4.5-6 $\mu \mathrm{m}$; basidioles numerous, similar to basidia but smaller. Basidiospores ellipsoid to subcylindrical, colorless, thin-walled, smooth, IKI-, CB-, 5-6 (-6.5) $\times 2.5-3 \mu \mathrm{m}, \mathrm{L}=$ $5.5 \mu \mathrm{m}, \mathrm{W}=2.7 \mu \mathrm{m}, \mathrm{Q}=2.1(\mathrm{n}=30 / 1)$.

Additional specimens examined - China, Guizhou Province, Xishui County, Xishui Nature Reserve, on fallen angiosperm branch, 6 July 2018, He5426 (BJFC 026487); Jiangxi Province, Fenyi County, Dagangshan Nature Reserve, on fallen angiosperm trunk, 18 September 2008, Dai 10468 (BJFC 004717).

Distribution - Guangdong, Guizhou and Jiangxi Provinces, southern subtropical China. 

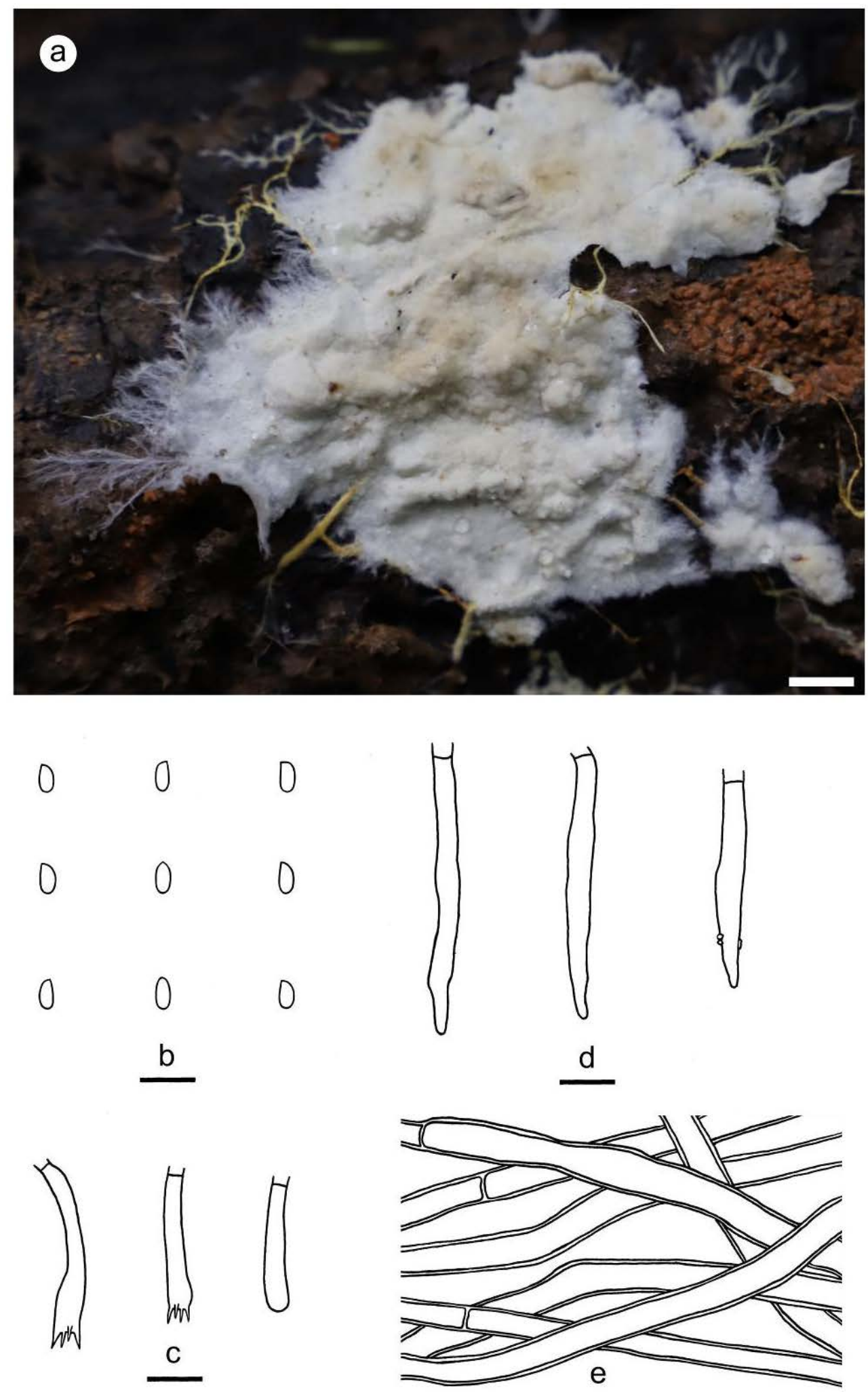

Figure 5 - Phanerochaete leptocystidiata (from the holotype He 5853). a basidiomata. b basidiospores. c basidia and a basidiole. $d$ cystidia. e hyphae from subiculum. Scale bars: $\mathrm{a}=1 \mathrm{~cm}$, b-e $=10 \mu \mathrm{m}$.

Notes - Phanerochaete leptocystidiata is characterized by the white to greyish orange pellicular basidiomata with hyphal cords and leptocystidia. In the phylogenetic tree, $P$. leptocystidiata, P. sinensis and P. burtii (Romell ex Burt) Parmasto formed a strongly supported clade (Fig. 1). Morphologically, the three species are very similar to each other by sharing 
pellicular basidiomata with hyphal cords and leptocystidia. Phanerochaete sinensis differs from $P$. leptocystidiata by having slightly shorter cystidia $(35-50 \mu \mathrm{m})$, slightly smaller basidiospores (4-5 $\times 2-2.5 \mu \mathrm{m})$ and a temperate distribution. Phanerochaete burtii differs from P. leptocystidiata by slightly shorter cystidia $(25-55 \mu \mathrm{m})$, slightly narrower basidiospores $(2-2.5 \mu \mathrm{m})$ and a distribution in U.S.A., Jamaica, Argentina, Brazil and Australia (Burdsall 1985, Hjortstam 2000). The P. burtii group is also morphologically similar to and phylogenetically close to $P$. sanguinea (Fr.) Pouzar group and P. carnosa (Burt) Parmasto. However, species of $P$. sanguinea group have orange to red basidiomata that usually stain the substrate with same color, whilst $P$. carnosa has an ochraceous hymenophore that turns dark green in KOH (Burdsall 1985, Xiong \& Dai 2009, Floudas \& Hibbett 2015).

Phanerochaete metuloidea Y.L. Xu \& S.H. He, sp. nov.

Fig. 6 MycoBank: MB 835449; Facesoffungi number: FoF 08035

Type - China, Yunnan Province, Jingdong County, Ailaoshan Nature Reserve, on fallen angiosperm branch, 24 August 2015, He 2565 (BJFC 021018, holotype).

Etymology - Refers to the presence of numerous lamprocystidia.

Fruiting body - Basidiomata annual, resupinate, widely effused, loosely adnate, easily detached from substrate, membranaceous to coriaceous, fragile after dried, up to $20 \mathrm{~cm}$ long, $6 \mathrm{~cm}$ wide. Hymenophore smooth, greyish orange [6B(3-4)], brownish orange [6C(3-4)] to light brown [6D(4-5)], turning reddish brown in $\mathrm{KOH}$, uncracked or sparsely cracked with age; margin thinning out, byssoid when juvenile, becoming indistinct with age, concolorous with hymenophore surface.

Microscopic structures - Hyphal system monomitic; generative hyphae mostly simple-septate, occasionally with single or double clamp connections. Subicular hyphae colorless, slightly thickwalled, moderately branched and septate, tightly interwoven, more or less parallel to substrate, 3-7 $\mu \mathrm{m}$ in diam. Cystidia (lamprocystidia) subulate to subfusiform, colorless, thick-walled, encrusted with crystals in the upper part, with a basal simple septum, occasionally with one or two secondary septa, projecting above the hymenium, 40-80 × 5-8 $\mu \mathrm{m}$. Basidia clavate, colorless, thin-walled, with a basal simple septum and four sterigmata, 40-70 × 5-8.5 $\mu \mathrm{m}$; basidioles numerous, similar to basidia but smaller. Basidiospores ellipsoid, colorless, thin-walled, smooth, IKI-, CB-, (4.5-) 5-6 $\times 2.5-3 \mu \mathrm{m}, \mathrm{L}=5.5 \mu \mathrm{m}, \mathrm{W}=2.8 \mu \mathrm{m}, \mathrm{Q}=2(\mathrm{n}=30 / 1)$.

Additional specimens examined - China, Fujian Province, Wuyishan County, Wuyishan Nature Reserve, on dead angiosperm branch, 17 August 2016, He 4463 (BJFC 023904); Jiangxi Province, Lianping County, Jiulianshan Nature Reserve, on fallen angiosperm trunk, 13 August 2016, He 4322 (BJFC 023764); Yunnan Province, Jingdong County, Ailaoshan Nature Reserve, on fallen angiosperm branch, 25 August 2015, He 2619 (BJFC 021065); Yongde County, Daxueshan Nature Reserve, on Quercus stump, 27 August 2015, He 2664 (BJFC 021104) \& He2675 (BJFC 021114), 28 August 2015, He 2766 (BJFC 021204); Yongping County, Baotaishan Forest Park, on base of living Quercus, 27 November 2015, He 3235 (BJFC 021630); on Quercus stump, 27 November 2015, He 3272 (BJFC 021667); Kunming, Panlong District, Yeyahu Park, on fallen angiosperm branch, 28 July 2014, He20140728-1 (BJFC 019238) \& He 20140728-14 (BJFC 019247); on living Quercus tree, 22 August 2015, He 2523 (BJFC 020976); Luquan County, Zhuanlong Town, on dead angiosperm branch, 4 December 2015, He3508a (BJFC 021905); Zhejiang Province, Kaihua County, Gutianshan Nature Reserve, on fallen angiosperm trunk, 12 August 2013, He 1799 (BJFC 016266) \& He 1806 (BJFC 016273).

Distribution - Southern China, mainly on Quercus.

Notes - Phanerochaete metuloidea is characterized by the presence of thick-walled lamprocystidia and long basidia. In macro-morphology, P. metuloidea is similar to P. laevis, $P$. sordida and $P$. burdsallii, but differs in having soft texture basidiomata, obviously thick-walled cystidia, and much longer basidia. In the phylogenetic tree, two samples of $P$. metuloidea formed a lineage sister to $P$. laevis and $P$. burdsallii, but distant from $P$. sordida (Fig. 1). Phanerochaete livescens (P. Karst.) Volobuev \& Spirin is similar to P. metuloidea by sharing thick-walled 
lamprocystidia, but differs in having ceraceous, ochraceous basidiomata, smaller basidia (16.4-27.2 $\times 3.9-5.0 \mu \mathrm{m})$ and a northern temperate distribution (Volobuev et al. 2015). Phanerochaete australis Jülich differs from $P$. metuloidea in having shorter but wider cystidia (38-56 × 7-10.8 $\mu \mathrm{m})$ and shorter basidia (20-25.8 × 4.3-5 $\mu \mathrm{m}$, Xiong \& Dai 2009).
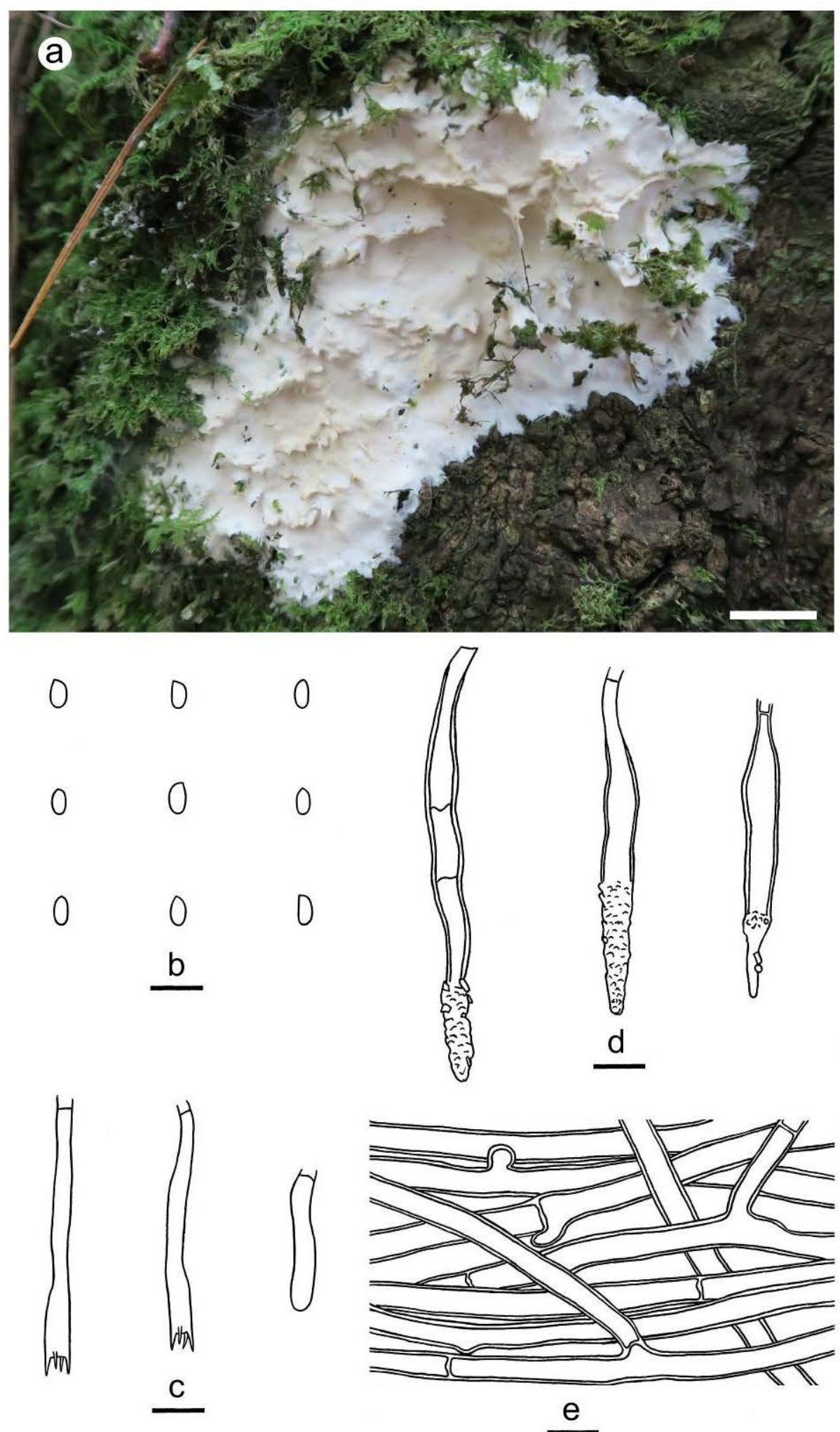

Figure 6 - Phanerochaete metuloidea (a from He 3235, b-e from the holotype He 2565). a basidiomata. b basidiospores. c basidia and a basidiole. $\mathrm{d}$ cystidia. e hyphae from subiculum. Scale bars: $\mathrm{a}=1 \mathrm{~cm}, \mathrm{~b}-\mathrm{e}=10 \mu \mathrm{m}$. 
MycoBank: MB 835450; Facesoffungi number: FoF 08027

Type - China, Hainan Province, Baoting County, Qixianling Forest Park, on rotten monocots culm, 11 June 2016, He 3988 (BJFC 022490, holotype).

Etymology - Refers to the small cystidia and basidiospores.

Fruiting body - Basidiomata annual, resupinate, effused, loosely adnate, easily detached from substrate, membranaceous, up to $15 \mathrm{~cm}$ long, $2 \mathrm{~cm}$ wide. Hymenophore smooth, light orange [6A(4-5)] to greyish orange [6B(3-6)], unchanged in $\mathrm{KOH}$, uncracked or sparsely and minutely cracked with age; margin thinning out, fimbriate or indistinct, concolorous with hymenophore surface.
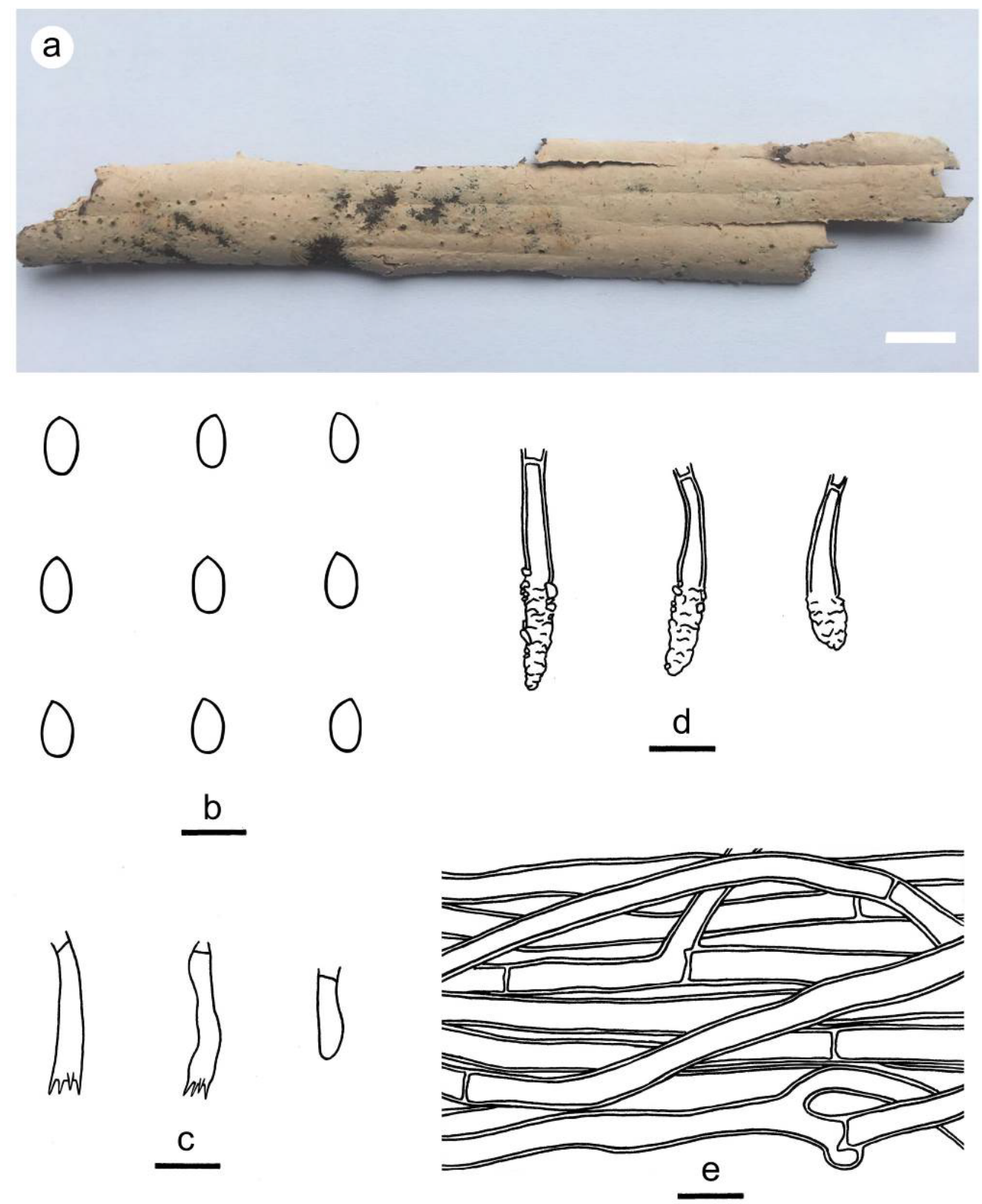

Figure 7 - Phanerochaete minor (from the holotype He 3988). a basidiomata. b basidiospores. c basidia and a basidiole. $d$ cystidia. e hyphae from subiculum. Scale bars: $\mathrm{a}=1 \mathrm{~cm}, \mathrm{~b}=5 \mu \mathrm{m}, \mathrm{c}-\mathrm{e}=$ $10 \mu \mathrm{m}$.

Microscopic structures - Hyphal system monomitic; generative hyphae mostly simple-septate, occasionally with single or double clamp connections. Subicular hyphae colorless, slightly thick- 
walled, moderately branched and septate, tightly interwoven, more or less parallel to substrate, 3-5 $\mu \mathrm{m}$ in diam. Cystidia (lamprocystidia) subcylindrical to subclavate, colorless, thick-walled, encrusted with crystals in the upper part, with a basal simple septum, occasionally with a secondary septum, projecting above the hymenium, 19-37 × 3-7 $\mu \mathrm{m}$. Basidia clavate, colorless, thin-walled, with a basal simple septum and four sterigmata, 15-21 × 3-5 $\mu \mathrm{m}$; basidioles numerous, similar to basidia but smaller. Basidiospores ellipsoid, colorless, thin-walled, smooth, IKI-, CB-, (3.5-) 4$4.6(-4.8) \times 2-2.5(-2.8) \mu \mathrm{m}, \mathrm{L}=4.2 \mu \mathrm{m}, \mathrm{W}=2.2 \mu \mathrm{m}, \mathrm{Q}=1.9(\mathrm{n}=30 / 1)$.

Additional specimen examined - China, Hainan Province, Wuzhishan County, Wuzhishan Nature Reserve, on rotten monocots culms, 11 June 2016, He 3977 (BJFC 022479).

Distribution - Hainan Province, southern tropical China.

Notes - Phanerochaete minor is characterized by the light orange basidiomata on monocots, short lamprocystidia, and small basidiospores. In the phylogenetic tree, two samples of $P$. minor formed a lineage sister to $P$. cystidiata, which differs in having cream to light yellow basidiomata and longer thin-walled cystidia (40-60 $\mu \mathrm{m}$, Wu et al. 2018a). A similar species, Phanerochaete flavidogrisea Sheng $\mathrm{H}$. Wu has yellowish grey hymenophore, small basidiospores (3-3.8 $\times 2-2.8$ $\mu \mathrm{m}$ ), and lacks cystidia (Wu 1998). Phanerochaete eburnea Sheng $\mathrm{H}$. Wu is similar to P. minor by sharing encrusted cystidia and small basidiospores, but differs in having ivory-colored hymenophore, longer cystidia $(30-60 \mu \mathrm{m})$ and subglobose basidiospores (3.7-4.7 × 2.8-3.2 $\mu \mathrm{m}$, Wu 1998).

Phanerochaete sinensis Y.L. Xu, C.C. Chen \& S.H. He, sp. nov.

Fig. 8

MycoBank: MB 835451; Facesoffungi number: FoF 08028

Type - China, Liaoning Province, Zhuanghe County, Xianrendong Forest Park, on fallen angiosperm branch, 5 August 2017, He 4660 (BJFC 024179, holotype).

Etymology - Refers to the distribution in China.

Fruiting body - Basidiomata annual, resupinate, effused, loosely adnate, easily detached from substrate, pellicular to membranaceous, up to $10 \mathrm{~cm}$ long, $4 \mathrm{~cm}$ wide. Hymenophore smooth, white (6A1), light orange (6A4) to greyish orange [6B(3-4)], slightly darkening in $\mathrm{KOH}$, uncracked or sparsely cracked when dried; margin thinning out, fibrillose or indeterminate, concolorous with hymenophore surface; hyphal cords white (6A1) to orange [6B(7-8)], turning reddish brown in $\mathrm{KOH}$.

Microscopic structures - Hyphal system monomitic; generative hyphae mostly simple-septate, occasionally with single or double clamp connections. Subicular hyphae colorless, slightly thickwalled, frequently branched and septate, loosely interwoven, more or less parallel to substrate, 3-7 $\mu \mathrm{m}$ in diam. Cystidia (leptocystidia) subcylindrical, slightly tapering toward apex, colorless, thinwalled, smooth, with a basal simple septum, projecting above the hymenium, 35-50 × 4-6 $\mu$ m. Basidia clavate, colorless, thin-walled, with a basal simple septum and four sterigmata, 17-22 × 4$5 \mu \mathrm{m}$; basidioles numerous, similar to basidia but smaller. Basidiospores ellipsoid to subcylindrical, colorless, thin-walled, smooth, IKI-, CB-, 4-5 (-5.5) $\times 2-2.5 \mu \mathrm{m}, \mathrm{L}=4.9 \mu \mathrm{m}, \mathrm{W}=2.2 \mu \mathrm{m}, \mathrm{Q}=$ $2.2(\mathrm{n}=30 / 1)$.

Additional specimens examined - China, Yunnan Province, Pingbian County, Daweishan Forest Park, on fallen angiosperm trunk, 11 November 2019, He 6189 (BJFC); Taiwan Province, Nantou County, Jenai Township, Aowanda National Forest Recreation Area, pine tree zone, $121^{\circ} 11^{\prime} \mathrm{E}, 23^{\circ} 56^{\prime} \mathrm{N}$, alt. $1300 \mathrm{~m}$, on fallen gymnosperm branch, 12 September 2018, GC 1809-56 (TNM).

Distribution - Liaoning, Yunnan and Taiwan Provinces of China.

Notes - Phanerochaete sinensis is characterized by the pellicular basidiomata with hyphal cords, presence of leptocystidia and subcylindrical basidiospores. It belongs to the $P$. burtii group, and morphologically almost indistinguishable from $P$. burtii, which, however, has longer basidia (25-35 $\mu \mathrm{m})$ and a distribution outside China. For other comparisons with similar species, see the discussions under $P$. leptocystidiata above. 

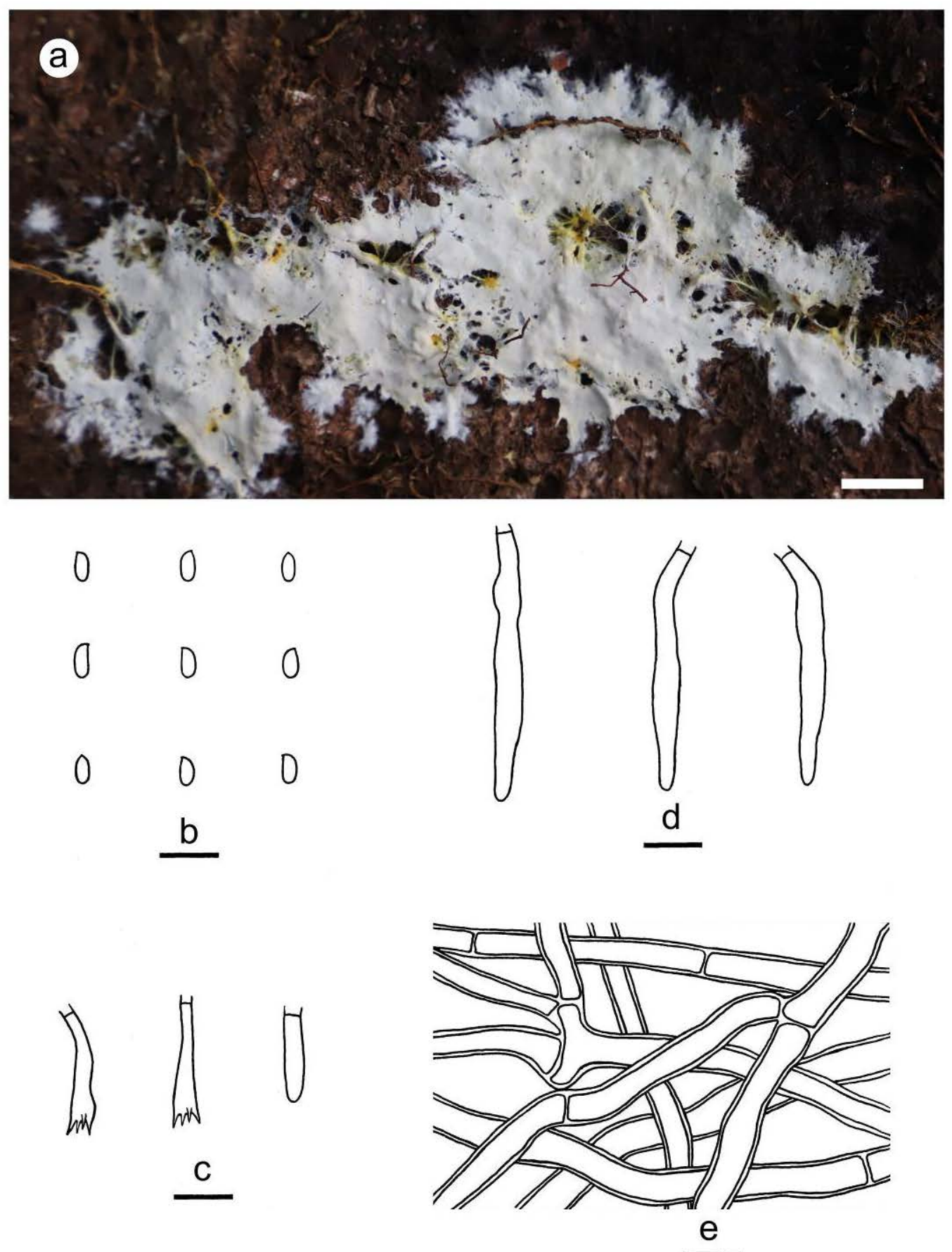

Figure 8 - Phanerochaete sinensis (a from He 6189, b-e from the holotype He 4660). a basidiomata; b. basidiospores; c. basidia and a basidiole; d. cystidia; e. hyphae from subiculum. Scale bars: $\mathrm{a}=1 \mathrm{~cm}, \mathrm{~b}-\mathrm{e}=10 \mu \mathrm{m}$

Phanerochaete subrosea Y.L. Xu \& S.H. He, sp. nov.

Fig. 9

MycoBank: MB 835452; Facesoffungi number: FoF 08029

Type - China, Ningxia Autonomous Region, Jingyuan County, Liupanshan Forest Park, on fallen angiosperm branch, 4 August 2015, He 2421 (BJFC 020874, holotype).

Etymology - Refers to the light pink to red basidiomata.

Fruiting body - Basidiomata annual, resupinate, effused, loosely adnate, easily detached from substrate, membranaceous, fragile after dried, up to $20 \mathrm{~cm}$ long, $3.5 \mathrm{~cm}$ wide. Hymenophore smooth, pale red (8A3), pastel red [8A(4-5)] to greyish red [8B(4-5)], turning purple in $\mathrm{KOH}$, 
uncracked; margin thinning out, fimbriate or indistinct, lighter or concolorous with hymenphore surface; hyphal cords concolorous with hymenophore, turning purple in $\mathrm{KOH}$.
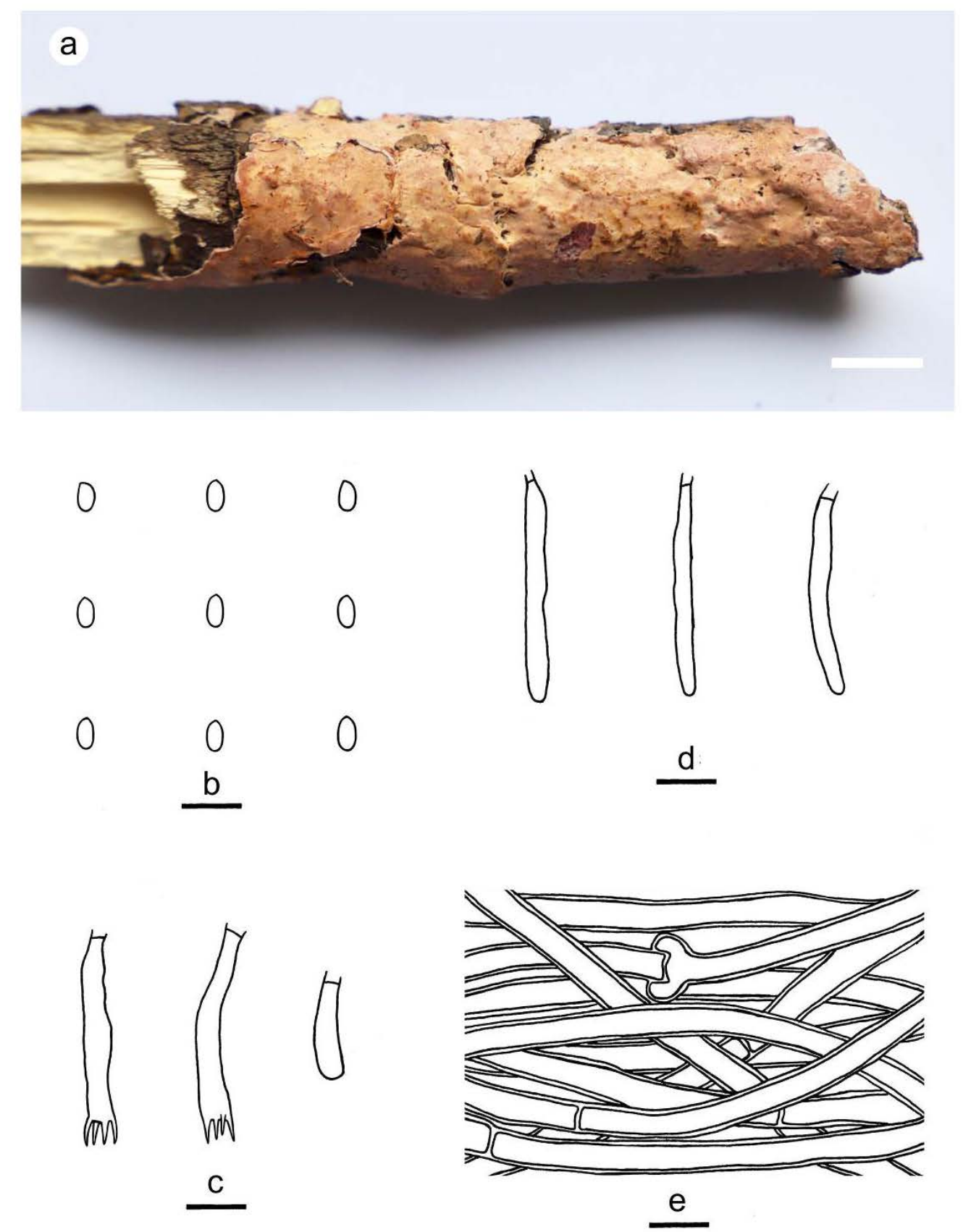

Figure 9 - Phanerochaete subrosea (from the holotype He 2421). a basidiomata. b basidiospores. c basidia and a basidiole. $d$ cystidia. e. hyphae from subiculum. Scale bars: $\mathrm{a}=1 \mathrm{~cm}, \mathrm{~b}-\mathrm{e}=10 \mu \mathrm{m}$

Microscopic structures - Hyphal system monomitic; generative hyphae mostly simple-septate, occasionally with single or double clamp connections. Subicular hyphae colorless, slightly thickwalled, moderately branched and septate, tightly interwoven, more or less parallel to substrate, 3-5 $\mu \mathrm{m}$ in diam. Cystidia (leptocystidia) subcylindrical, colorless, thin-walled, smooth, with a basal simple septum, projecting above the hymenium, 33-55 × 3-5 $\mu \mathrm{m}$. Basidia clavate, colorless, thinwalled, with a basal simple septum and four sterigmata, 24-36 $\times 4.5-5.5 \mu \mathrm{m}$; basidioles numerous, similar to basidia but smaller. Basidiospores ellipsoid, colorless, thin-walled, smooth, IKI-, CB-, 5-6 (-6.5) × 2.5-3 $\mu \mathrm{m}, \mathrm{L}=5.3 \mu \mathrm{m}, \mathrm{W}=2.8 \mu \mathrm{m}, \mathrm{Q}=1.9(\mathrm{n}=30 / 1)$.

Distribution - Ningxia Autonomous Region, northwest China. 
Notes - Phanerochaete subrosea is characterized by the light pink to red basidiomata turning purple in $\mathrm{KOH}$ and subcylindrical leptocystidia. Morphologically, the $P$. sanguinea group resembles $P$. subrosea by sharing the more or less red basidiomata with hyphal cords and presence of leptocystidia, but differs in turning black in $\mathrm{KOH}$ and staining the substrate with reddish orange color (Burdsall 1985, Bernicchia \& Gorjón 2010, Floudas \& Hibbett 2015). Phanerochaete carnosa is also similar to P. subrosea, but differs in having basidiomata turning green in $\mathrm{KOH}$, subulate cystidia and slightly smaller basidiospores (Burdsall 1985). In the phylogenetic tree, $P$. subrosea is not closely related to the $P$. sanguinea group and $P$. carnosa, but forms a lineage with a sequence of $P$. krikophora (HHB-5796). However, this lineage received low support values from all analyses, and the latter name was not officially published and represented a species with clamp connections (Fig. 1, Floudas \& Hibbett 2015). Phanerochaete subrosea resembles species of Rhizochaete Gresl., Nakasone \& Rajchenb. by sharing the membranaceous basidiomata and hyphal cords turning purple in $\mathrm{KOH}$, but they are not phylogenetically closely related (Greslebin et al. 2004).

Phanerochaete yunnanensis Y.L. Xu \& S.H. He, sp. nov.

Fig. 10

MycoBank: MB 835478; Facesoffungi number: FoF 08030

Type - China, Yunnan Province, Yongde County, Daxueshan Nature Reserve, on dead liana, 27 August 2015, He 2719 (BJFC 021157, holotype).

Etymology - Refers to the type locality in Yunnan Province, southwest China.

Fruiting body - Basidiomata annual, resupinate, effused, closely adnate, membranaceous to coriaceous, up to $20 \mathrm{~cm}$ long, $2.5 \mathrm{~cm}$ wide. Hymenophore grandinioid with small dense granules, pale orange (6A3), light orange $[6 \mathrm{~A}(4-5)]$ to greyish orange [6B(3-6)], unchanged in $\mathrm{KOH}$, uncracked at first then densely cracked with age; margin thinning out, distinct, white, byssoid, becoming thick and indistinct with age.

Microscopic structures - Hyphal system monomitic; generative hyphae mostly simple-septate, occasionally with single or double clamp connections. Subicular hyphae colorless, thick-walled, moderately branched and septate, interwoven, more or less parallel to substrate, 3-5 $\mu \mathrm{m}$ in diam. Cystidia absent. Encrusted hyphae present, cylindrical, projecting above the hymenium, more or less grouped together. Basidia clavate to subcylindrical, colorless, thin-walled, with a basal simple septum and four sterigmata, $15-35 \times 3.5-5 \mu \mathrm{m}$; basidioles numerous, similar to basidia but smaller. Basidiospores ellipsoid to subcylindrical, colorless, thin-walled, smooth, IKI-, CB-, 4.5-6 × 2-3 $\mu \mathrm{m}, \mathrm{L}=5.6 \mu \mathrm{m}, \mathrm{W}=2.5 \mu \mathrm{m}, \mathrm{Q}=2.2(\mathrm{n}=30 / 1)$.

Additional specimens examined - China, Yunnan Province, Yongde County, Daxueshan Nature Reserve, on dead Quercus branch, 27 August 2015, He 2697 (BJFC 021136); 28 August 2015, He 2741 (BJFC 021179); Wenshan County, Laojunshan Nature Reserve, on dead angiosperm branch, 13 November 2019, He 6233.

Distribution - Yunnan Province, southwest China.

Notes - Phanerochaete yunnanensis is characterized by the light yellow grandinioid basidiomata, encrusted hyphae in hymenium, and absence of cystidia. Phanerochaete granulata Sheng $\mathrm{H}$. Wu from Taiwan is similar to P. yunnanensis by sharing grandinioid basidiomata and absence of cystidia, but differs in lacking encrusted hyphae in hymenium and slightly shorter basidiospores (3.7-4.5 $\mu \mathrm{m}, \mathrm{Wu} 2007)$. In addition, the ITS DNA sequences of type specimens of the two species are largely different (data not shown). Phanerochaete reflexa Sheng $\mathrm{H}$. Wu is similar to $P$. yunnanensis by having uneven hymenophore and lacking cystidia, but differs in having tuberculate hymenophore with a reflexed margin (Wu 1998). Phanerochaete subquercina (Henn.) Hjortstam is similar to P. yunnanensis by sharing the odontioid hymenophore and absence of cystidia, but differs in having longer aculei and thin-walled hyphae, and lacks the encrusted hyphae in hymenium (Bernicchia \& Gorjón 2010). Phanerochaete aculeata Hallenb. also has odontioid hymenophore, but differs from $P$. yunnanensis in having encrusted cystidia (Bernicchia \& Gorjón 2010). In the phylogenetic tree, $P$. yunnanensis formed a sister lineage to P. robusta, but the latter can be easily distinguished by having smooth hymenophore and two kinds of cystidia (Wu 
et al. 2018b). Morphologically, P. yunnanensis resembles Hyphodermella corrugata (Fr.) J. Erikss. \& Ryvarden, which also has grandinioid hymenophore and encrusted hyphae in hymenium, and lacks cystidia. However, they are not phylogenetically closely related.
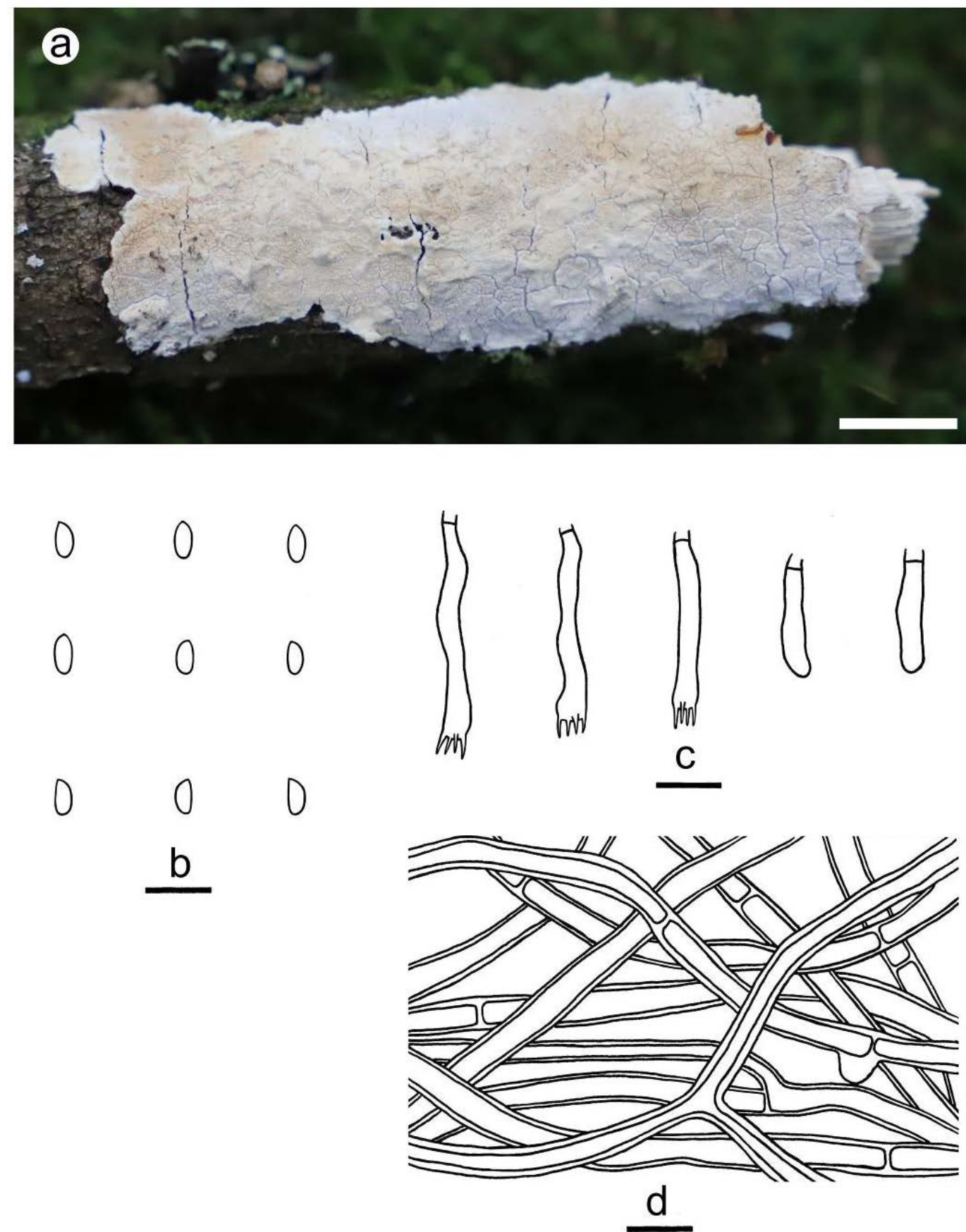

Figure 10 - Phanerochaete yunnanensis (a from He 6233; b-d from the holotype He 2719). a basidiomata. $\mathrm{b}$ basidiospores. c basidia and basidioles. $\mathrm{d}$ hyphae from subiculum. Scale bars: $\mathrm{a}=1$ cm, b-d = $10 \mu \mathrm{m}$.

\section{Discussion}

At present, species of Phanerochaete s.s. show a great diversity with a broad range of morphological characters, for example, basidiomata may be smooth, grandinioid to poroid with different color reactions in $\mathrm{KOH}$, subicular hyphae are colorless or brown, cystidia are absent or if present then smooth or heavily encrusted etc. So far, there does not seem to be any specific 
morphological characters that can be used to delimit or subdivide the genus. In addition, no distinct subclades with strong support values can be recognized in the Phanerochaete clade.

Phanerochaete albida Sheng $\mathrm{H}$. Wu from Taiwan, China was sequenced for the first time. The Chinese samples of $P$. australis, $P$. carnosa, $P$. citrinosanguinea Floudas \& Hibbett, $P$. concrescens Spirin \& Volobuev, P. cumulodentata (Nikol.) Parmasto, P. ericina (Bourdot) J. Erikss. \& Ryvarden, P. laevis, P. livescens, P. magnoliae (Berk. \& M.A. Curtis) Burds., P. sordida and $P$. velutina (DC.) P. Karst. formed strongly supported lineages with samples from other countries. Phanerochaete canobrunnea and P. stereoides originally described from Taiwan, China, were also collected in Sri Lanka by us. Surprisingly, the specimen from Sri Lanka (He 5778) formed a well-supported lineage with the temperate species $P$. chrysosporium Burds. (HHB-6251sp). The species $P$. taiwaniana Sheng $\mathrm{H}$. Wu was also found in Vietnam. The sequences of $P$. argillacea Sheng $\mathrm{H}$. Wu and $P$. canolutea Sheng $\mathrm{H}$. Wu, but not from type materials, clustered together with strong support values. It is probable that the two sequences represent the same species but this requires further study.

Phanerochaete fusca Sheng $\mathrm{H}$. Wu, C.C. Chen \& C.L. Wei and P. porostereoides have brown hymenophores and subicular hyphae; they formed a strongly supported lineage in our analyses. The ITS similarity (within 563 base pairs) of type specimens of the two species is $99.3 \%$. Moreover, the type localities of the two species are very close. According to Wu et al. (2018a), $P$. fusca differs from $P$. porostereoides in possessing cystidia and larger basidiospores (5.7-7.3 $\times 3-$ $3.5 \mu \mathrm{m}$ vs. 4.7-5.3 × 2.5-3.1 $\mu \mathrm{m}$ ). However, Liu \& He (2016) observed hyphal ends that are similar to cystidia in $P$. porostereoides. Because the basidiospores are rare in the two specimens of $P$. porostereoides studied herein, only a narrow range of basidiospore sizes was obtained. The evidence presented here shows that $P$. fusca is a later synonym of $P$. porostereoides.

Xiong \& Dai (2009) recorded 19 names of Phanerochaete s.l. in China, among which eight species, P. affinis (Burt) Parmasto (= P. laevis), P. australis, P. burtii, P. carnosa, P. sanguinea, P. sordida, P. stereoides and P. velutina, belong to Phanerochaete s.s. (Floudas \& Hibbett 2015, Liu \& He 2016). Except for P. burtii and P. sanguinea, the other six species in China were confirmed by our analyses. However, based on the descriptions and illustrations in Dai \& Xiong (2012), it is possible that $P$. burtii sensu Xiong \& Dai (2009) may represent $P$. leptocystidia or $P$. sinensis, since they are very similar in morphology. The occurrence of $P$. sanguinea in China needs further studies.

Ghobad-Nejhad et al. (2015) reported the new species, P. aurantiobadia Ghobad-Nejhad, S.L. Liu \& E. Langer from northeast China that was later treated as a synonym of P. robusta by Spirin et al. (2017) and Wu et al. (2018b). Liu \& He (2016) described a new species, P. porostereoides and recorded $P$. brunnea in mainland China. Miettinen et al. (2016) proposed the new combination of $P$. inflata (B.S. Jia \& B.K. Cui) Miettinen, which has typical poroid hymenophore and was originally described from China as Ceriporia.

In addition to the nine new species described above, we also report the occurrence of nine more Phanerochaete species - P. bambucicola Sheng H. Wu, $P$. citrinosanguinea, $P$. concrescens, $P$. cumulodentata, $P$. ericina, $P$. incarnata Sheng $H$. Wu, $P$. livescens, $P$. magnoliae and $P$. taiwaniana in mainland China for the first time. A total of 28 species of Phanerochaete s.s. is now known from mainland China.

Corticioid fungi is a large group of wood-inhabiting fungi with simpler fruiting body and fewer distinguishing morphological features when compared with polypores and mushrooms, but its species and phylogenetic diversity is even higher and less intensively studied (Bernicchia \& Gorjón 2010, Larsson et al. 2004, Binder et al. 2005). A large amount of corticioid taxa have not been discovered and described worldwide especially in the subtropical-tropical areas. As shown in this study and earlier ones (Volobuev et al. 2015, Chen et al. 2018, Ordynets et al. 2018), DNA sequence data are very useful in exploring cryptic taxa and diversity of corticioid fungi. Thus, in order to understand the diversity, phylogeny and evolution of the fungi, future taxonomic and phylogenetic work should focus more on the corticioid group by using both molecular and morphological characters. 
Key to 28 Phanerochaete s.s. species in mainland China

1. Hymenophore poroid P. inflata

1. Hymenophore non-poroid. 2

2. Hymenophore grandinioid P. yunnanensis

2. Hymenophore smooth to raduloid 3

3. Hymenophore at first smooth, odontioid to raduloid when mature ............................................ 4

3. Hymenophore smooth to more or less tuberculate

4. Distributed in northern China

P. cumulodentata

4. Distributed in southern China P. magnoliae

5. Basidiomata with hyphal cords 6

5. Basidiomata without hyphal cords. 10

6. Hymenophore and hyphal cords purple in $\mathrm{KOH}$....

P. subrosea

6. Hymenophore and hyphal cords not purple in $\mathrm{KOH}$ 7

7. Hyphal cords reddish brown. P. citrinosanguinea

7. Hyphal cords cream to yellow 8

8. Cystidia obviously encrusted with crytals $P$. laevis

8. Cystidia smooth or sparsely encrusted 9

9. Cystidia 30-70 × 4-6 $\mu \mathrm{m}$; basidiospores $5-6 \times 2.5-3 \mu \mathrm{m}$. P. leptocystidiata

9. Cystidia 35-50 × 4-6 $\mu \mathrm{m}$; basidiospores $4-5 \times 2-2.5 \mu \mathrm{m}$. $P$. sinensis

10. Subicular hyphae brown 11

10. Subicular hyphae colorless to pale yellow. .. 14

11. Hymenophore brown

P. porostereoides

11. Hymenophore gray to grayish brown 12

12. Cystidia present P. stereoides

12. Cystidia absent 13

13. Subicular hyphae loosely interwoven, clamps present; hyphidia absent P. brunnea

13. Subicular hyphae tightly interwoven; clamps absent, hyphidia present.... P. cinerea

14. Cystidia obviously encrusted 15

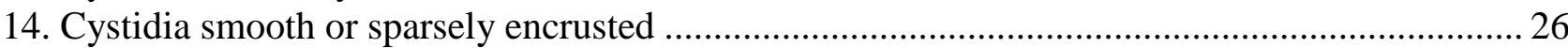

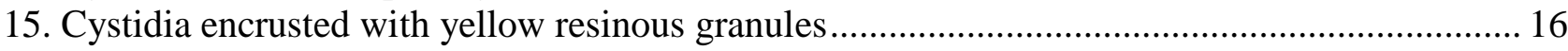

15. Cystidia encrusted with white crystals 17

16. Hymenophore brown; quasi-binding hyphae present

P. ericina

16. Hymenophore lilac pink; quasi-binding hyphae absent

P. incarnata

17. On Monocotyledons. P. minor

17. On Dicotyledons 18

18. Cystidia up to $150 \mu \mathrm{m}$ long P. velutina

18. Cystidia up to $80 \mu \mathrm{m}$ long 19

19. Cytidia up to $13 \mu \mathrm{m}$ wide 20

19. Cytidia up to $9 \mu \mathrm{m}$ wide 21

20. Cystidia only apically encrusted; widely distributed in north and south. P. concrescens

20. Cystidia encrusted in up to one third of the length; distributed only in south.

21. Hymenophore yellow to buff.

.P. australis

21. Hymenophore white to cream. 22

22. Basidiomata ceraceous; basidiospores $>5.5 \mu \mathrm{m}$ long .24

22. Basidiomata membranaceous, basidiospores $<5.5 \mu \mathrm{m}$ long. $P$. livescens

23. Hymenophore yellow to yellowish brown; margin determinate 23

23. Hymenophore cream to light yellow; margin fibrillose ides

24. Cystidia thick-walled; basidia up to $70 \mu \mathrm{m}$ long, $8.5 \mu \mathrm{m}$ wide. P. cystidiata

24. Cystidia thin- to slightly thick-walled; basidia up to $50 \mu \mathrm{m}$ long, $6 \mu \mathrm{m}$ wide P. metuloidea

25. Subicular hyphae thin to slightly thick-walled; cystidia subulate P. laevis

25. Subicular hyphae thick-walled; cystida tapering but with obtuse apex

P. sordida 


\section{Acknowledgements}

The authors would like to express their deep appreciations to Prof. Yu-Cheng Dai (Beijing Forestry University, China) for allowing us to study his specimens. The research was supported by the National Natural Science Foundation of China (Nos. 31870011 \& 31750001).

\section{References}

Alvarado P, Moreau PA, Dima B, Vizzini A et al. 2018 - Pseudoclitocybaceae fam. nov. (Agaricales, Tricholomatineae), a new arrangement at family, genus and species level. Fungal Diversity 90, 109-133.

Bernicchia A, Gorjón SP. 2010 - Fungi Europaei 12. Corticiaceae s.l. Edizioni Candusso, Alassio, $1008 \mathrm{p}$.

Binder M, Hibbett DS, Larsson KH, Larsson E et al. 2005 - The phylogenetic distribution of resupinate forms across the major clades of mushroom-forming fungi. Systematics and Biodiversity 3, 113-157.

Burdsall HH Jr. 1985 - A contribution to the taxonomy of the genus Phanerochaete. Mycologia Memoirs 10, 1-165.

Chen CC, Wu SH, Chen CY. 2018 - Hydnophanerochaete and Odontoefibula, two new genera of phanerochaetoid fungi (Polyporales, Basidiomycota) from East Asia. MycoKeys 39, 75-96.

Cui BK, Li HJ, Ji X, Zhou JL et al. 2019 - Species diversity, taxonomy and phylogeny of Polyporaceae (Basidiomycota) in China. Fungal Diversity 97, 137-392.

Dai YC, Xiong HX. 2012 - Flora fungorum sinicorum vol. 42 Corticiaceae s.l. (1). Science Press, Beijing, 198 p.

Darriba D, Taboada GL, Doallo R, Posada D. 2012 - jModelTest 2: more models, new heuristics and parallel computing. Nature Methods 9, 772.

de Koker T, Nakasone KK, Haarhof J, Burdsall HH Jr, Janse BJH. 2003 - Phylogenetic relationships of the genus Phanerochaete inferred from the internal transcribed spacer region. Mycological Research 107, 1032-1040.

Desjardin DE, Perry BA. 2018 - The genus Pluteus (Basidiomycota, Agaricales, Pluteaceae) from Republic of São Tomé and Príncipe, West Africa. Mycosphere 9, 598-617.

Eriksson J, Hjortstam K, Ryvarden L. 1978 - The Corticiaceae of North Europe vol. 5: Mycoaciella - Phanerochaete. Fungiflora, Oslo, pp 987-1047.

Floudas D, Hibbett DS. 2015 - Revisiting the taxonomy of Phanerochaete (Polyporales, Basidiomycota) using a four gene dataset and extensive ITS sampling. Fungal Biology 119, 679-719.

Ghobad-Nejhad M, Liu SL, Langer E, Dai YC. 2015 - Molecular and morphological evidence reveal a new non-cystidiate species belonging to the core Phanerochaete (Polyporales). Mycological Progress 14, 68

Greslebin AG, Nakasone KK, Rajchenberg M. 2004 - Rhizochaete, a new genus of phanerochaetoid fungi. Mycologia 96, 260-271.

Hall TA. 1999 - Bioedit: a user-friendly biological sequence alignment editor and analysis program for Windows 95/98/NT. Nucleic Acids Symposium Series 41, 95-98.

Hapuarachchi KK, Elkhateeb WA, Karunarathna SC, Cheng CR et al. 2018a - Current status of global Ganoderma cultivation, products, industry and market. Mycosphere 9, 1025-1052. 
Hapuarachchi KK, Karunarathna SC, Raspé O, De Silva KHWL et al. 2018b - High diversity of Ganoderma and Amauroderma (Ganodermataceae, Polyporales) in Hainan Island, China. Mycosphere 9, 931-982.

Hapuarachchi KK, Karunarathna SC, Phengsintham P, Yang HD et al. 2019 - Ganodermataceae (Polyporales): Diversity in Greater Mekong Subregion countries (China, Laos, Myanmar, Thailand and Vietnam). Mycosphere 10, 221-309.

Hjortstam K. 2000 - Two new species of Phanerochaete (Basidiomycotina, Aphyllophorales), and a key to species from subtropical and tropical areas. Karstenia 40, 53-62.

Jia BS, Zhou LW, Cui BK, Rivoire B, Dai YC. 2014 - Taxonomy and phylogeny of Ceriporia (Polyporales, Basidiomycota) with an emphasis of Chinese collections. Mycological Progress 13, 81-93.

Justo A, Miettinen O, Floudas D, Ortiz-Santana B et al. 2017 - A revised family-level classification of the Polyporales (Basidiomycota). Fungal Biology 121, 798-824.

Katoh K, Rozewicki J, Yamada KD. 2017 - MAFFT online service: multiple sequence alignment, interactive sequence choice and visualization. Briefings in Bioinformatics. bbx108.

Kearse M, Moir R, Wilson A, Stones-Havas S et al. 2012 - Geneious Basic: An integrated and extendable desktop software platform for the organization and analysis of sequence data. Bioinformatics 28, 1647-1649.

Kornerup A, Wanscher JH. 1978 - Methuen handbook of colour. 3rd Ed. E. Methuen and Co., Ltd., London, 252 p.

Larsson KH. 2007 - Re-thinking the classification of corticioid fungi. Mycological Research 111, 1040-1063.

Larsson KH, Larsson E, Koljalg U. 2004 - High phylogenetic diversity among corticioid homobasidiomycetes. Mycological Research 108, 983-1002.

Liu SL, He SH. 2016 - Phanerochaete porostereoides, a new species in the core clade with brown generative hyphae from China. Mycosphere 7, 648-655.

Maddison WP, Maddison DR. 2018 - Mesquite: a modular system for evolutionary analysis. Version 3.5.1. http://www.mesquiteproject.org.

Miettinen O, Spirin V, Vlasák J, Rivoire B et al. 2016 - Polypores and genus concepts in Phanerochaetaceae (Polyporales, Basidiomycota). MycoKeys 17, 1-46.

Ordynets A, Scherf D, Pansegrau F, Denecke J et al. 2018 - Short-spored Subulicystidium (Trechisporales, Basidiomycota): high morphological diversity and only partly clear species boundaries. MycoKeys 35, 41-99.

Phookamsak R, Hyde KD, Jeewon R, Bhat DJ et al. 2019 - Fungal diversity notes 929-1035: taxonomic and phylogenetic contributions on genera and species of fungi. Fungal Diversity 95, 1-273.

Ronquist F, Teslenko M, van der Mark P, Ayres DL et al. 2012 - MrBayes 3.2: Efficient Bayesian phylogenetic inference and model choice across a large model space. Systematic Biology 61, 539-542.

Sádlíková M, Kout J. 2017 - A new Phanerochaete (Polyporales, Basidiomycota) with brown subicular hyphae from Thailand. Mycosphere 8, 1024-1030.

Spirin V, Volobuev S, Okun M, Miettinen O, Larsson KH. 2017 - What is the type species of Phanerochaete (Polyporales, Basidiomycota)? Mycological Progress 16, 171-183.

Stamatakis A. 2014 - RAxML Version 8: A tool for phylogenetic analysis and post-analysis of large phylogenies. Bioinformatics 30, 1312-1313.

Swofford DL. 2002 - PAUP*: Phylogenetic analysis using parsimony (*and other methods). Version 4.0b10. Sinauer Associates, Sunderland, Massachusetts.

Volobuev S, Okun M, Ordynets A, Spirin V. 2015 - The Phanerochaete sordida group (Polyporales, Basidiomycota) in temperate Eurasia, with a note on Phanerochaete pallida. Mycological progress 14, 80.

White TJ, Bruns T, Lee S, Taylor J. 1990 - Amplification and direct sequencing of fungal ribosomal RNA genes for phylogenetics. In: Innis MA, Gelfand DH, Sninsky JJ, White TJ 
(eds.), PCR Protocols: A guide to methods and applications. Academic Press, San Diego, pp 315-322.

Wu SH. 1990 - The Corticiaceae (Basidiomycetes) subfamilies Phlebioideae, Phanerochaetoideae and Hyphodermoideae in Taiwan. Acta Botanica Fennica 142, 1-123.

Wu SH. 1995 - A study of the genus Phanerochaete (Aphyllophorales) with brown subicular hyphae. Mycotaxon 54, 163-172.

Wu SH. 1998 - Nine new species of Phanerochaete from Taiwan. Mycological Research 102, 1126-1132.

Wu SH. 2000 - Six new species of Phanerochaete from Taiwan. Botanical Bulletin of Academia Sinica, 41. 165-174.

Wu SH. 2004 - Two new species of Phanerochaete from Taiwan. Mycotaxon 90, 423-429.

Wu SH. 2007 - Three new species of corticioid fungi from Taiwan. Botanical Studies 48, 325-330.

Wu SH, Chen CC, Wei CL. 2018a - Three new species of Phanerochaete (Polyporales, Basidiomycota). MycoKeys 41, 91-106.

Wu SH, Chen YP, Wei CL, Floudas D, Dai YC. 2018b - Two new species of Phanerochaete (Basidiomycota) and redescription of P. robusta. Mycological Progress 17, 425-435.

Wu SH, Nilsson HR, Chen CT, Yu SY, Hallenberg N. 2010 - The white-rotting genus Phanerochaete is polyphyletic and distributed throughout the phlebioid clade of the Polyporales (Basidiomycota). Fungal Diversity 42, 107-118.

Wu F, Zhou LW, Yang ZL, Bau T, Dai YC. 2019 - Resource diversity of Chinese macrofungi: edible, medicinal and poisonous species. Fungal Diversity 98, 1-76.

Xiong HX, Dai YC. 2009 - Notes on lignicolous corticioid fungi in China 3. Phanerochaete (Basidiomycota, Polyporales) in China. Mycosystema 28, 29-35. 